Anal Chem. 2006 June 15; 78(12): 3965-3984. doi:10.1021/ac060637m.

\title{
Electrochemical Sensors
}

Eric Bakker ${ }^{1}$ and Yu Qin ${ }^{2}$

${ }^{1}$ Department of Chemistry, 560 Oval Drive, Purdue University, West Lafayette, IN 47907

${ }^{2}$ Department of Chemistry, Renmin University of China, Beijing, People's Republic of China

\section{Introduction}

This review gives an overview of electrochemical sensor research for the calendar years 2004 and 2005. References were collected by topic and author searches using databases such as ACS SciFinder. Since searches with sensor-related keywords are normally not as meaningful because of the vast use of the term sensor in the chemical sciences, we also manually skimmed through tables of contents of journals to identify key publications. Unfortunately, the limit of 200 references made it impossible to comprehensively cover the entire field of electrochemical sensors. Instead, emphasis was on fundamental advances of sensing principles, materials and characteristics. Only original and review articles published in widely available journals written in English were considered. Patents, book chapters or book serials were omitted for this review. Applications, including electronic tongues and noses, are not covered here either to give more room for fundamental advances.

Today, electrochemical sensors are tightly integrated and hyphenated with sampling, fluidic handling, separation and other detection principles. Unfortunately, this review does not has sufficient room to cover these topics, and a reader should keep in mind that the topic of electrochemical sensors is relatively mature and has found its way into commercial products and advanced integrated sensing systems. Again, the focus here was on the reporting of fundamental advances, not so much on fabrication, integration and hyphenation.

As in past years, we have organized this review by topic, in the order of potentiometric, voltammetric and gas sensors as well as reference electrodes that generally avoid the use of biological recognition elements, followed by electrochemical biosensors including affinity sensing principles. It should be emphasized that many such biosensors are not sensors in the strict sense, as their response behavior is often not reversible.

Please keep in mind that this is a subjective collection of publications. Given the rather vast and active field of electrochemical sensor research, it is inevitable that this review gives an incomplete account of the status of the field. The authors apologize in advance for any possible oversights of important contributions, as they are bound to have occurred. Nonetheless, it should give the reader a snapshot of current activity in this important field, and hopefully will provide motivation for further work on the understanding and development of chemical sensors. 


\section{Potentiometric Sensors}

\section{Reviews}

Wroblewski et al. published a review on the design and performance of miniaturized chemical sensors based on silicon transducers ( 30 references). 1 The groups of Cha and Nam gave a review on their efforts to design ionophores based on molecular tweezer shapes, especially to recognize carbonate, calcium, silver and other ions ( 42 references). 2 The article also describes new ionophores not reported before. In line with his earlier critical examination of the practical determination of potentiometric sensor selectivity, Macca reviewed the current and previous IUPAC recommendations on how the response time of ion-selective electrodes (ISEs) should be reported and showed that most authors are not complying with them ( 72 references). 3 There have been numerous debates in the past about the exact response mechanism of ion-selective electrodes. A review summarized the applicability of the rather intuitive so-called phase boundary potential model, with many literature examples (119 references). 4 Another review mainly aimed at the more general analytical chemistry community and published in a special issue on trace level analysis, outlined the current state of the art of potentiometric sensors for measurements at trace levels (64 references).5

\section{ISEs: New Mechanisms, Unusual Analytes}

Solvent polymeric ion-selective electrodes tend to be insensitive to localized surface adsorption phenomena because their response mechanism is governed by the thermodynamics of ion extraction. Muslinkina and Pretsch showed that the surface active concanavilin A can be detected without labeling by binding to a stearyl-b-d-glucopyranoside layer adsorbed onto an ion-selective membrane. ${ }^{6}$ This was accomplished with electrochemical impedance spectroscopy and with non-equilibrium potentiometry, where the membrane is interrogated upon concentration polarizing the Nernst diffusion layer. In a related approach, Xu et al. were able to monitor the surface adsorption of electrically neutral surfactant Brij35 onto ion-selective membranes by a pulsed galvanostatic approach where sample ions are also depleted in the Nernst diffusion layer. Here, however, this process is instrumentally controlled and leads to reversible sensor signals (see also Voltammetry: ITIES). ${ }^{7}$

Non-equilibrium potentiometry is a promising technique that widens possible applications of ion-selective electrodes. Historically, however, steady-state concentration gradients across ion-selective membranes have been too slow to establish across such membranes and resulted in potential drifts. Tompa et al. showed that thin ion-selective supported liquid membranes may reach steady-state in a matter of seconds. ${ }^{8}$ Interestingly, concentration changes at the inner membrane side had an immediate effect on the transmembrane ion fluxes, which could lead to sensor applications where calibration is performed at the inner side of the membrane without perturbing the sample.

Meyerhoff and co-workers explored the potentiometric response of dinonylnaphthalenesulfonate doped polyurethane membranes to cationic dendrimers. ${ }^{9}$ While the response mechanism is analogous to that of previously reported polycation-selective membranes, it is notable that different dendrimeric generations gave essentially the same equilibrium potential change, but shifted the non-equilibrium response at short measuring times to lower concentrations down to $5 \mathrm{nM}$ in agreement with the increase in dendrimer charge.

Yong-Yuan Chen and coworkers proposed a potentiometric sensor for ascorbic acid on the basis of cobalt phthalocyanine nanoparticles directly coated on a glassy carbon electrode by drop caoting. ${ }^{10}$ The authors explained the selective and rapid response to ascorbic acid on the basis of the redox potential, with cobalt acting as the mediator. 


\section{ISEs: Materials, lonophores, lon-Exchangers}

The introduction of new ion recognition chemistries has historically been at the heart of ionselective electrode research, and remains to be important today. Egorov and co-workers found that the replacement of a long chain alkyl substituent at the nitrogen atom of quaternary ammonium salts by a methyl group may drastically improve the ion-selectivity of corresponding ISEs towards divalent ions. ${ }^{11}$ Such selectivity tunability on the basis of the ionexchanger alone has often been overlooked in the past.

In related work, Alaviuhkola et al. synthesized five different aromatic borate anions to be used as ion-recognition sites in ISEs for the detection of aromatic cations on the basis of $\pi-\pi$ interactions. ${ }^{12}$ While the selectivity differences among various ion-exchangers amounted to about one order of magnitude, the results show again that the structure of the ion-exchanger may play a significant role in the ion recognition process if no other ionophore is present in the membrane.

Many papers dealt with the design and characterization of anion-selective receptors, traditionally a more difficult task than sensors for cations. Gorski et al. reported that Zirconium (IV)-salophens exhibit very high fluoride selectivity over most lipophilic anions including perchlorate. ${ }^{13}$ Membranes contained a lipophilic cation-exchanger, suggesting a so-called charged carrier mechanism, and functioned for about 2 weeks.

Zirconium(IV)tetraphenylporphyrins were studied by Yuchi and co-workers who found by UV-Vis spectroscopy that the hydroxide-bridged dimerization equilibrium of this compound in the membrane depends on the concentration and nature of the contacting solution. ${ }^{14} \mathrm{~A}$ strong preference for acetate or citrate anions was found in select cases, although with significant super-Nernstian response slopes.

Since dimerization reactions of metalloporphyrins are often the source for undesired superNernstian response slopes (usually accompanied by sluggish response times) and short lifetimes because of precipitation, Qin and Bakker proposed to covalently attach two different In(III) porphyrin derivatives to alleviate this problem. ${ }^{15}$ The resulting membranes indeed showed no evidence for dimer formation and showed Nernstian response slopes to chloride ions, although the measuring range was now limited to lower concentrations because of the increased effective complex formation constant of the ionophore.

Ortuño et al. explored tris(2-aminoethyl)amine as an ionophore for the recognition of nitrate in ISEs. ${ }^{16}$ While it appears questionable that the control experiment without ionophore exihibited virtually no anion response characteristics and the ionophore has limited lipophilicity, the nitrate selectivity appeared to improve about 10-fold relative to conventional ISEs.

Le Goff et al. covalently attached a derivative of the phosphate-selective ionophore 3decyl-1,5,8-triazacyclodecane-2,4-dione, originally developed by Carey and Riggan, to a crosslinked polystyrene-block-polybutadiene-block-polystyrene polymer for improved durability. ${ }^{17}$ Long-term stability was improved to about $40 \mathrm{~d}$ with an attractive ion selectivity that was similar to that of a membrane containing freely dissolved ionophore.

Boswell and Buhlmann reported on the use of fluorous phases as a novel class of sensing materials for ISEs. ${ }^{18}$ Since such materials are known to exhibit negligible extraction of many potential interferences they bear great promise for this research field. Of course, all active sensing ingredients must be made compatible with this sensing matrix, which demands a significant synthetic effort. This paper already demonstrates that cation-exchanger based 
membranes are fully functional and show exceptionally wide selectivity ranges that cannot be achieved with other sensing materials.

While sol-gel matrices have mainly been used in biosensor applications because of their encapsulation properties, they are also being explored as ion-selective electrode materials. Park and co-workers encapsulated the traditional carbonate ionophore trifluoroacetyl-pdecylbenzene together with a lipophilic anion-exchanger into a sol-gel matrix prepared from the precursors (3-isocyanopropyl)-triethoxysilane and hexadecyltrimethoxysilane. ${ }^{19}$

Suprisingly, the resulting carbonate selectivities were significantly improved relative to PVC membranes containing the same receptor, which the authors attributed to the increased hydrophilicity of the sol-gel matrix. In an effort to improve durability and biocompatibility Marxer and Schoenfisch reported on sol-gel based $\mathrm{pH}$ sensors containing covalently atached amine functionalities.20 Potentiometric response characteristics were attractive, and the authors demonstrated a reduced level of platelet adhesion relative to traditional sensing matrices.

The groups of Cha and Nam also demonstrated that previously reported chloride sensors based on simple expoxy resins cured with polyamine-type hardeners, effectively forming anionexchanger sites, can be successfully used for chloride measurements in physiological samples including whole blood. ${ }^{21}$ The chloride selectivities are significantly improved relative to traditional ion-exchanger based systems, especially over lipophilic interferences.

Neutral red electropolymerized onto platinum electrodes was studied spectroscopically and potentiometrically, and an unusual deviation from a linear $\mathrm{pH}$ response slope was observed when carboxylic acids were present in the sample. ${ }^{22}$ Consequently, the authors found that such electrodes showed remarkable selectivity to citrate over many other carboxylic anions, sufficient for successful citrate determinations in soft drinks.

While potentiometric sensors with so-called solid inner contacts at the back side of the ionselective membrane have been known for many years, research on these systems have experienced a resurgence. Some of this is attributed to the quest of achieving low detection limits (see there), but much of this research is driven for the need for durable and maintenancefree sensors that can be mass produced.

Lindfors and Ivaska offered a critical look at the stability of polyaniline solid contact layers for use in potassium-selective electrodes by UV-Vis, cyclic voltammetry and open circuit potentiometry. 23 While the sensing membrane appears to hinder the emeraldine saltemeraldine conversion of the conducting polymer, the water uptake of the inner film was probably responsible for significant long-term potential drifts (see also24).

An all-solid-contact chloride sensor was reported on the basis of a mixture of lipophilic conducting polymer poly(3-octylthiophene), a highly lipophilic anion-exchanger trihexadecylmethylammonium chloride for improved durability, PVC and plasticizer, deposited onto a glassy carbon disk electrode. ${ }^{25}$ The electrode showed acceptable long term stability with sufficient durability for practical use. The group of Ivaska also characterized the sensing properties of undoped poly(3-octylthiophene) itself, without covering ion-selective membrane, and found a preference for silver ions with Nernstian response slopes, even for undoped polymer films, and no evidence for polymer oxidation by silver ions.26 This again suggests that POT is resistant to oxidation, which, together with its lipophilic character makes it an attractive candidate for solid contact ISEs as supported also by other works discussed in this review. Brzozka and Malinowska and co-workers studied various ferrocene terminated disulfide self-assembled monolayers on gold as solid inner contact systems, and long term stabilities with phenyl-spaced derivatives compared favorable to hydrogel inner contact 
systems.27 For this purpose, oxygen, carbon dioxide and water layer tests were critically performed and a drastic improvement was observed compared to bare gold underlayers.

Chaniotakis and coworkers explored the use of gallium nitride semiconductor materials for potentiometric anion sensors. ${ }^{28}$ Here, anion recognition is based on adsorption processes on the gallium face of the (0001) GaN crystal in analogy to early work on CdS based membranes, but unfortunately the reported ion selectivities were not impressive.

\section{ISEs: Lowering Detection Limits}

The discovery that ion-selective electrodes may reach detection limits orders of magnitude lower than previously believed continues to fuel this chemical sensor field. Most research appears now to focus on solid-contact ion-selective electrodes and other sensing configurations where the inner solution at the backside of the membrane is either absent or not relevant to the practical performance characteristics of the electrode. This is important because it eliminates tedious optimization steps that were necessary for previous configurations.

Among many other papers, Michalska and co-workers studied calcium-selective electrodes with a poly(pyrrole) solid contact that was doped with the complex ligand Tiron, and a subnanomolar detection limit was reported after exploring various conditioning protocols. ${ }^{29}$ Electrode drifts and repeatabilities were also critically evaluated and found to deteriorate somewhat with increased sample dilution. In other work, Michalska and Maksymiuk used a galvanostatic polarization step on the final electrode assembly containing either poly(pyrrole), poly(N-methylpyrrole) and poly(3,4ethelenedioxythiophene) as conducting polymer solid contact before measurement. 30 This was reportedly done to compensate for the spontaneous charging/discharging reaction of the conducting polymer, which is accompanied by an undesired transport of ions across the membrane.

Sutter et al., on the other hand, used poly(pyrrole) by electropolymerizing it with a redox buffer, potassium hexacyanoferrate(II)/(III) on platinum to fabricate lead(II)-selective electrodes with nanomolar detection limits without such a galvanostatic preconditioning step. ${ }^{24}$ The authors performed reconditioning steps on their electrodes that helped them eliminate an undesired water layer between membrane and solid contact. The resulting electrodes were virtually free of long-term drifts, suggesting that such water layers, rather than spontaneous discharge reaction of the polymer, may be responsible for long term instabilities. The same group then reported on solid-contact ion-selective electrodes with nanomolar detection limits for lead(II) by using poly(octylthiophene) as a more lipophilic and less oxidizable conducting polymer in conjunction with methylmethacrylate-decylmethacrylate ion-selective membranes. 31 This polymer shows drastically reduced diffusion coefficients and improved adhesion compared to classical plasticized PVC. This combination allowed the authors to avoid the use of any water soluble mediator, such as Triton or hexacyanoferrate, thereby making these systems even more robust and practically applicable. Michalska and co-workers also found that the use of methacrylic/acrylic polymers with lower diffusion coefficients decreased the detection limit of solid-contact potassium-selective electrodes. 32

The influence of the inner solution composition on the detection limit of ion-selective electrodes was also eliminated by covalent attachment of the ionophore. Püntener et al. synthesized a derivative of the lead(II)-selective ionophore 4-tert-butylcalix[4] arene-tetrakis $\left(N, N^{\prime}\right.$-dimethylthioacetamide) and copolymerized it to form a polyurethane membrane. ${ }^{33} \mathrm{~A}$ nanomolar detection limit was found that was much less influenced by the composition of the inner solution than classical membranes containing freely dissolved ionophores.

Poly(styrene-co-divinylbenzene) based monolithic columns ordinarily used for liquid chromatography were introduced as ion-selective membrane materials after doping them with 
plasticizer, ionophore and ion-exchanger for the construction of calcium, silver and sodiumselective electrodes for low detection limit measurements. ${ }^{34}$ The detection limits (1-10 nM) did not depend on the inner solution composition because of the long diffusion distance between outer and inner sides and the low porosity of the capillaries, making this a very promising alternative to solid contact based systems.

The time-dependent concentration profiles and corresponding cell potentials of ion-selective membranes at or near detection limit and containing an aqueous inner solution were described by a numerical approximation. ${ }^{35}$ This work helped understand the time scale upon which steady-state is reached across the membrane, required conditioning times for optimum measuring characteristics, and practical response times and drifts.

In view of lowering the detection limit of silver-selective membranes, Nam and co-workers reported on the synthesis and characterization of 12 new tweezer-type ionophores based on steroid backbones containing dithiocarbamoyl moieties. ${ }^{36}$ The interferences by mercury ions were carefully evaluated and the best membranes were reported to exhibit sub-nanomolar detection limits. The group of Malinowska also characterized silver-selective ionophores, 16membered azothia- and azoxythiacrown ethers, with attractive selectivities, although the achieved detection limits were not as low. ${ }^{37}$

\section{ISEs: Characterizations, Spectroscopic Studies}

Gyurcsanyi and Lindner offered an experimental approach to the characterization of transmembrane ion fluxes in view of lowering the detection limit with so-called spectroelectrochemical microscopy. ${ }^{38}$ While similar imaging experiments had been described before, including the use of electrochemical perturbation, this paper offers systematic insight into membranes with imposed transmembrane currents. Subsequently, Langmaier and Lindner showed with this technique that some phenoxazine dyes (nile blue derivatives) so widely used in optical sensors and polymeric $\mathrm{pH}$ electrodes may photochemically decompose easily under certain conditions that were not studied earlier. ${ }^{39}$

Since diffusion coefficients in the membrane phase have an important impact on the attainable detection limit of the resulting potentiometric sensors, they were studied experimentally in more detail. Long and Bakker monitored the backdiffusion of dye into a previously photobleached spot on the membrane to quantify the diffusion coefficients in materials containing a variety of plasticizer/PVC ratios and added inert lipophilic electrolyte. 40 The results agreed with earlier data. Heng, Toth and Hall determined apparent diffusion coefficients from optical sensor response experiments for methacrylic-acrylic sensing matrices, and found that they were orders of magnitude smaller than for plasticized PVC. ${ }^{41}$ This result was subsequently used to fabricate ISEs with lower detection limits (see above).

Established ISE theory regards ion-selective membranes as homogeneous systems. The group of Buhlmann used dark field visible microscopy and FTIR microspectroscopy to study membranes where self-aggregation takes place. Results were used to explain drastic differences in the response behavior of sulfate selective electrodes containing structurally similar derivatives of bisthiourea ionophores. ${ }^{42}$

Pejcic and De Marco use a range of surface analysis techniques to understand aging processes of a variety of chalcogenide based ISEs. In one example, a combination of XPS, SEM and electrochemical impedance analysis was used on mercury-selective electrodes based on the chalcogenide AgBr-Ag2S-As2S3-HgI2. ${ }^{43}$ The complementary techniques revealed photooxidation, hydration and arsenic depletion and surface adsorption of mercury and variety of halides. 


\section{Reference Electrodes}

The reference electrode is an integral part of an electrochemical measurement, and efforts in miniaturization and simplification of electrochemical measuring systems often fail because of the need of large electrolyte reservoirs and liquid junctions. While research on new reference electrodes has been limited to a few papers, there has been renewed interest compared to previous years.

The group of Lewenstam introduced a conducting polymer with $\mathrm{pH}$ buffering ligands as a new reference electrode concept. ${ }^{44}$ The systems appear to work quite well, especially at physiological $\mathrm{pH}$. While the mechanism is not completely understood at this stage, the reference electrode appears to at least partly act as a self-buffering system. As the $\mathrm{pH}$ buffer partitions from the polymer film into the sample may maintain a local $\mathrm{pH}$ that is independent of the sample $\mathrm{pH}$ in a certain range.

Maksymiuk and co-workers also used conducting polymers to construct reference electrodes. 45 In one approach, conducting polymers were fabricated to exhibit no ion-exchange properties. In agreement with theoretical expectations, the resulting open circuit potentials were independent of electrolyte concentration, but dependent on the nature of the electrolyte. To also suppress redox interferences, a pseudo-reference electrode was constructed by covering such polymers with PVC films that contained excess of potassium chloride, and the resulting potentiometric behavior was convincing.

Ha et al. used polymeric junction membrane on the basis of cellulose acetate and polyurethane to solid state reference electrodes that can in principle be mass produced. ${ }^{46}$ While there were no new chemical principles reported, the design offers good adhesion, hydration from the outside sample within $100 \mathrm{~s}$, and a useful lifetime of up to $90 \mathrm{~min}$.

Lowy and coworkers characterized a previously reported miniaturized reference electrode based on a silver sulfide inner reference element embedded into an acrylic copolymer matrix for use in biological and organic media. ${ }^{47}$ The polymeric intermediate layer appears to essentially eliminate the electrode slope of the inner reference element to either silver and sulfide, but no convincing explanations were given here for this behavior.

A microtubular hydrogen electrode was proposed by Kunimatsu et al. as a miniaturized replacement of the traditional hydrogen electrode, ${ }^{48}$ but the electrode was found to only function in contact with acidic solutions.

\section{Voltammetric Sensors}

\section{Reviews}

The group of Bond made a strong case that the time honored representations of electrochemical waveforms may be easily Fourier transformed for a presentation in the frequency domain (24 references). ${ }^{49}$ This allows one to reduce interferences and to separate Faradaic from background currents, for instance.

Umezawa and coworkers reviewed the design of ion channel sensors based on artificial receptors (30 references). ${ }^{50}$ Most of these sensor concepts rely on a redox marker present in solution that is denied access to the electrode surface upon binding of the substrate to a surfaceconfined receptor.

Amatore and Maisonhaute elaborated in a thoughtful review about the experimental challenges involved with submicrosecond time scale measurements (34 references). 51 The problems associated with the ohmic drop are discussed, along with strategies to perform ohmic drop 
compensation, followed by specific examples that include long range electron transfer reactions. Some reviews described the use and application of new materials. Note that a number of book series include or are devoted to the electrochemistry of modified diamond electrodes, which are not cited here. As part of an award account, Niwa reviewed the electroanalytical utility of carbon film electrodes, including micro and nanostructured ones (84 references).52 He stresses that such films possess a wider potential window than metal electrodes, are less prone to adsorption processes, can be fabricated into microarray electrodes and can achieve low detection limits. Economou gave a critical look at bismuth-film electrodes, materials that have the promise to replace mercury based electrodes (34 references).53 They are attractive mainly because of their low toxicity and partial insensitivity to dissolved oxygen, and are well suited for stripping analysis. Their only main drawback appears to be their limited anodic range. Walcarius described the impact of mesoporous silica-based materials, which have similar sieving characteristics as zeolites, on electrochemistry (145 references).54 Such materials are attractive because of their highly ordered structure and very high specific surface area and their ease of functionalization. The authors give examples, including stripping analysis, electrocatalysis, bioelectrochemistry and gas sensors. Zen and Kumar reviewed clay mineral electrodes for chemical sensor applications (43 references). 55 The authors describe the preparation, key characteristics, and a number of practical examples, including stripping analysis and enzyme biosensor development. Molecularly imprinted polymer films for electrochemical sensors, mostly their own work, were reviewed by Blanco-Lopez et al. (35 references).56 Four different designs were compared: electrogenerated polymer films, drop coated films, composite acrylic PVC films and spin coated acrylic films.

Town and van Leeuwen comparatively evaluated various modes of stripping chronopotentiometry for trace level speciation analysis (66 references). ${ }^{57}$ The authors stress the advantages of depletive stripping potentiometry at scanned deposition potential, which including greater resolution and, in some cases, improved selectivity, and include some theory. Hanrahan et al. reviewed the design, development and applications of electrochemical sensors for environmental monitoring ( 71 references). 58 This review touched only briefly on the operational principles and mainly emhasized a variety of in-situ measurement examples. Trojanowicz and Wcislo summarized progress in the design of enantioselective sensors and biosensors, starting with the initial beginnings some 25 years ago. 59 This review encompasses the description of a variety of materials and transduction principles, including molecularly imprinted polymers, immunosensors, enzyme biosensors, and ion-selective electrodes.

Samec et al. reviewed progress of realizing amperometric ion sensors on the basis of ion amperometry at the interface between two immiscible electrolyte solutions (105 references).

60 The authors emphasize that the technology may now be sufficiently mature for routine use and possible commercialization, and describe multi-analyte detection and sensors for a number of non-electroactive ions and polyions.

The group of Hauser wrote a review with 95 references on amperometric sensors for gaseous electroactive analytes where the measurement takes place at the contact zone between gaseous sample, electrolyte and solid electrode. ${ }^{61} \mathrm{~A}$ number of new developments have appeared in recent years, and sensors for $\mathrm{SO}_{2}, \mathrm{NO}_{\mathrm{x}}, \mathrm{O}_{3}, \mathrm{CO}$, formaldehyde, ethanol and other gases have been fabricated.

\section{Ion Transfer Voltammetry}

This area of research experiences renewed activity and has moved even closer from the fundamental studies at the interface of two immiscible electrolyte solutions (ITIES) to useful chemical sensors. Kihara and coworkers reported on the coulometric detection of ions such as potassium, magnesium and calcium by using a flow cell that operates on the principles of ion transfer voltammetry. ${ }^{62}$ Each ion was detected separately within 40 -s by passing through a 
porous Teflon tube with inserted silver wire and quantitative transfer into a contacting organic solution containing the counter electrode and a suitable ionophore. This exciting paper has implications for calibration-free ion detection as well as quantitative removal of unwanted interferences for a number of applications.

Shao and coworkers showed that dopamine can be detected voltammetrically by transfer into a 1,2-dichloroethane phase doped with a variety of crown ethers, with a detection limit down to $50 \mathrm{nM}$ when measured with differential pulse voltammetry. ${ }^{63}$ The key motivation for ion transfer voltammetry is the lack of interference by ascorbic acid, which is a problem with other electrochemical techniques.

Yuan and Amemiya used cyclic voltammetry and chronoamperometry at micropipettes containing dichloroethane and dinonylnaphthalenesulfonate to detect the polycation protamine, an antidote for the blood anticoagulant heparin. ${ }^{64}$ The key advantage of this technique over zero current potentiometry appears to be its improved reversibility, and the possibility of direct protamine detection without having to rely on competing sodium ions. This paper was mainly of mechanistic nature, evaluating the complex stoichiometry and explaining the nature of protamine extraction on the basis of an adsorption/transfer model. In a related effort, the same research group described the voltammetric detection of the anticoagulant polyanion heparin at similarly configured micropipettes, with octadecyltrimethylammonium as the heparin recognizing reagent in the organic phase. ${ }^{65}$ Fundamental studies suggested that polyion adsorption, rather than complete transfer was the relevant mode of detection and a voltammetric stripping analysis technique was developed to detect heparin down to 0.01 units per $\mathrm{mL}$. This is a somewhat puzzling conclusion since earlier, analogous ion-selective electrodes were confirmed to exhibit heparin transport across the bulk of the membrane. Whole blood experiments were also demonstrated successfully with the technique.

Shvarev and Bakker characterized a previously reported pulsed galvanostatic technique for the reversible detection of the polycation protamine. ${ }^{66}$ Unlike the system mentioned above, an imposed current pulse forces the extraction of protamine and sodium ions into the membrane in analogy to zero current potentiometric sensors, but exhibits sensor reversibility because of an intermittent baseline potential pulse that is applied. This paper demonstrates the utility of this sensor for the detection of heparin in undiluted whole blood via heparin-protamine titration. Makarychev-Mikhailov et al. extended on this technique by introducing a zero current measurement pulse between the current and baseline potential pulse. ${ }^{67}$ Ion-selective membranes interrogated with this triple pulse technique are termed pulstrodes and allow one to separate the ion extraction from the measurement step, thereby eliminating the undesired $\mathrm{iR}$ drop. It was applied to the super-sensitive detection of silver ions with up to 20 -fold increased electrode slopes.

Traditionally, sensors based on ion transfer voltammetry are thought to respond linearly to concentration changes, while signals of the corresponding potentiometric sensors depend on logarithmic concentrations. This apparent contradiction was revisited by Sutter et al. with a thorough theoretical explanation and corresponding experimental results, ${ }^{68}$ explaining that the exact relationship depends on the nature of the kinetic limitation.

\section{Voltammetric Sensors: Spectroelectrochemical Sensors, Coupled Selectivity, Chemometrics, Heated Electrodes}

Voltammetric technique generally only reach low detection limits in combination with an accumulation or catalytic step. Potentiometric sensors, in contrast, are today capable of subnanomolar detection limits (see above). In response, so-called programmed potential sweep voltammetry was introduced by Yoo and Park to decrease the detection limit to sub-nanomolar 
levels. ${ }^{69}$ The technique involves using an input waveform that results in a greatly diminished background current in the potential region of interest, and was applied to the measurement of dopamine with an estimated detection limit of $127 \mathrm{pM}$. A possible challenge of this interesting technique is the requirement of prior knowledge of the background signal, which may be problematic in the measurement of unknown samples.

Voltammetric sensors have been coupled to other detection/recognition principles in order to achieve a higher dimensionality of the device. Of course, this approach is very well established in Analytical Chemistry to couple, for instance, separation systems with chemical detectors that possess some type of selectivity. Electrophoresis separation with electrochemical detection really is in the a realm of electroanalysis, and so are many others. This review, however, focuses on distinct sensing principles and cannot possibly cover the countless hyphenation examples reported in the literature that involve electrochemical principles as well.

The group of Heineman has continued its work on spectroelectrochemical sensing based on such hyphenated detection techniques, often combining selective recognition, cyclic voltammetric analyte turnover, and optical detection. In one recent paper, this group reported on the use of 2,9-dimethyl-1,10-phenanthroline embedded in a Nafion-SiO2 composite film coated onto an indium tin oxide transparent electrode to induce an electrochemically mediated ligand exchange reaction for copper ethylenediamine complexes in the sample.70 This reaction was modulated by cyclic voltammetry and resulted in a large optical response of the sensor. This group has also reported on attenuated total internal reflectance spectroscopic detection of stripping voltammetry of metals such as lead and mercury. ${ }^{71}$ The optical rather than electrochemical detection results in less than optimal detection limits $(2.5 \times 10-7 \mathrm{M})$, but allows for convenient multianalyte detection and the presence of oxygen in the sample.

Buffle and coworkers had previously reported on permeation liquid membrane coupled with optical or electrochemical detection in the receiving solution for the design of sensing systems with orthogonal selectivity. In recent work, Salauen and Buffle described a theoretical description of such systems, based on steady-state considerations but taking into account the geometry of the cell. ${ }^{72}$ Predictions with this theory were successfully applied to experimental results for lead and cadmium detection in non-complexing media.

Wiyaratn et al. described a simple but highly sensitive electrochemical collector-generator process to detect organohalides with a $0.1 \mathrm{nM}$ detection limit. ${ }^{73}$ Analyte electrolysis and release of halide ions was achieved at a first Zn/PTFE composite working electrode, followed by the detection of the released halides at a second silver working electrode by cathodic stripping voltammetry. The continuous collection of electrolysis product at the second electrode for a period of 600-s was responsible for the low detection limit. This work was followed by the synthesis of a Pt-Zn porphyrin nanocomposite material, which was stabilized in Nafion membranes and used on glassy carbon electrodes as catalytic material for the detection of organohalides, including chloroform, carbontetrachloride, chlorobenzene and others. ${ }^{74}$ Measuring ranges were observed from 0.5 to $10 \mu \mathrm{M}$, making this a promising material. Since a number of years, chemometrics is playing an increasing role to enhance the dimensionality of analytical data. Morena et al. used differential pulse voltammetry at a platinum electrode, which is normally used as a detection method after chromatographic separation, coupled with multivariate calibration methods to differentiate the voltammetric waves, and were able to simultaneously detect the amino acids tryptophan, cysteine and tyrosine. ${ }^{75}$ The method was successfully applied to the analysis of oxidizable amino acids in feed samples.

The group of Wightman has done important work to devise fast scan voltammetric sensors for the detection of neurotranmitters such as dopamine. In a recent paper, they applied principal component analysis to resolve different neutrotransmitters from cyclic voltammetric data that 
would ordinarily overlap electrochemically. ${ }^{76}$ Five principal components were found to be relevant from a 30 scan calibration set, and successfully applied to the identification and quantitation of unknowns if up to two 2 neurotransmitters were present.

Bond and coworkers demonstrated the use of large-amplitude fourier transformed highharmonic alternating current cyclic voltammetry to discriminate against capacitive background currents, separate reversible from overlapping irreversible processes and the kinetic resolution of reversible electrochemical processes. ${ }^{77}$

The direct electrochemical detection of NADH can be difficult because adsorption and polymerization processes can lead to electrode deactivation and fouling. Lau et al. solved this problem by using heated platinum electrodes, representing the first example of using localized electrode heating to minimize surface fouling effects. ${ }^{78}$

Elevated temperatures were also used by Zen et al. to improve peak separation in mixtures of dopamine and uric acid, and to suppress ascorbic acid as well (also note the ion transfer voltammetry work cited above to eliminate ascorbic acid interference).$^{79}$ In this work, however, the entire sample was heated to the desired temperature (50 C), which appears to be a less elegant approach.

Clark and Fritsch explored to effect of magnetohydrodynamics on anodic stripping voltammetry. ${ }^{80}$ When excess mercury(II) was added to the sample during deposition of various metal ions, the Lorentz force increased the convection and hence resulted in up to $130 \%$ peak current enhancements.

The group of Compton found that the application of a low frequency sound during the deposition step decreased the detection limit for arsenic hundred-fold in square wave anodic stripping voltammetry, also by enhancing mass transport. ${ }^{81}$ The low frequency sound was found to be attractive in view of miniaturizing the system.

In an interesting variation on this general theme, Weber and Messerschmidt found that stirring the sample during the stripping step gave an order of magnitude lower detection limits for the adsorptive stripping voltammetric detection of platinum $(0.2 \mathrm{pg}$ in a $15 \mathrm{~mL}$ sample $) .{ }^{82}$ The enhancement was much less pronounced for other metals and was chiefly explained by the convective enhancement of the catalytic hydrogen process during the stripping process.

\section{Voltammetric Sensors: Materials}

The concept of molecularly imprinted polymers (MIPs) continues to fascinate researchers because of its intuitive beauty, ruggedness and versatility. While most research in this direction is targeted to the design of chromatographic stationary phases, their use in electrochemical sensors is expanding for electroactive analytes. In convincing work, the group of Mandler explored sol-gel polymers imprinted with the organophosphate pesticide parathion and performed gas phase and liquid phase partitioning experiments as well as cyclic voltammetric studies. ${ }^{83}$ Imprinted films showed a more than 10 -fold increased equilibrium binding over nonimprinted polymers, and discriminated well against a range of other structurally similar organophosphates.

Guoli Shen and coworkers reported on the covalent molecular imprinting of p-phtahlic acid (as a template for the noncovalent interaction with p-hydroquinone) into a $\mathrm{TiO} 2$ network on a graphitic electrode. ${ }^{84}$ Cyclic voltammetry and infrared spectroscopy revealed a roughly thousand-fold apparent binding constant enhancement on the basis of the imprinting process. In a special volume of Analytica Chimica Acta devoted to molecularly imprinted polymers, Pogorelova et al. reported on $\mathrm{TiO} 2$ films as well, imprinting benzylphosphonic acids and 
thiopenols.85 FTIR was used to follow the association complex during imprinting, and ISFETs were fabricated and showed some enhanced selectivity.

Kitade et al. developed a potentiometric immunosensor based on a molecular imprinted polymer instead of a traditional antibody. ${ }^{86}$ The sensor used serotonin as the template and a $\mathrm{Pt}$ electrode as the transducer. The sensor exhibited superior selectivity to serotonin over tryptamine, acetaminophen, or procainamide. The authors applied the sensors to micro total analysis systems in view of simplified clinical analysis.

Hui-Jing Liang et al. examined the enantioselectivity of polypyrrole films to recognize D and L-tyrosine. ${ }^{87}$ While enantioselectivities of more than 9:1 were reported, diffusion kinetics, not only binding affinities, appeared to play a significant role in the electrochemical recognition and discrimination step.

Tuñon-Blanco and coworkers used a computational approach to enable the rational design of MIPs for chemical sensing. ${ }^{88}$ Density functional theory calculations were used to pre-screen for the most suitable monomer and polymerization solvent for the imprinting of a given target template. The predictions included possible interferences and were validated by experiment using an electrochemical sensor for homovanillic acid as a model system.

Aldakov and Anzenbacher described phosphate-selective p-doped conductive polymers that can be interrogated via conductivity measurements as well as by optical means, by spacing positive charges along the polymer chain for optimal coulombic interactions with phosphate. ${ }^{89}$ Among the few anions explored in this study, chloride showed weak interactions while fluoride was found to be a major interference and gave similar signals as pyrophosphate.

Lee and Park found that glucose can be directly electrochemically detected without using any enzyme at a boron-doped diamond electrode. ${ }^{90}$ This was accomplished in the physiological concentration range, even in treated human blood samples, and no interferences from ascorbic acid or uric acid were found. The key drawback of this methodology appears to be the need for an alkaline $\mathrm{pH}$, making it difficult to realize in-situ monitoring in undiluted blood or in subcutaneous tissue.

Electrochemical enzyme-less sugar recognition was also the goal of Miyahara and Kurihara, who explored langmuir-blodgett films containing a carotenoid amphiphile functionalized with a boronic acid residue. ${ }^{91}$ When a mannoside sugar containing a nitrobenzene moiety as redox marker was present in the sample, cyclic voltammetry showed increased current responses of the device. Selectivities for this early system are not expected to be high, but such data were not given in the paper.

Diamond electrodes were also successfully explored by the group of Swain for metal ion analysis in environmental samples in an effort to replace the mercury based electrode materials that are no longer attractive today. ${ }^{92}$ The authors found nanocrystalline diamond thin-film electrodes to have attractive properties for the measurement of $\mathrm{Pb}(\mathrm{II}), \mathrm{Ag}(\mathrm{I}), \mathrm{Cu}(\mathrm{II}), \mathrm{Cd}(\mathrm{II})$ and $\mathrm{Zn}$ (II) in a variety of samples when interrogated with differential pulse voltammetry.

Alternatively, Yantasee et al. explored carbon paste electrodes modified with a self-assembled monolayer of an acetamide phosphonic acid on mesoporous silica to detect $\mathrm{Cd}(\mathrm{II}), \mathrm{Cu}$ (II) and $\mathrm{Pb}$ (II) at a mercury-free electrode material. ${ }^{93}$ The detection with adsorptive stripping voltammetry yielded detection limits down to $0.5 \mathrm{ppb}$ after a 20 min preconcentration time. Yoon-Bo Shim and coworkers synthesized two redox active crown ethers to study their binding affinity and to fabricate ammonium-selective chronoamperometric sensors by embedding them into a Nafion coating of a glassy carbon electrode. 94 The amperometric response was generated from the redox active quinone functionalities. Interestingly, the authors reported only marginal 
interferences from 9 different alkali and alkaline earth metals provided in 200 -fold excess. The drastic enhancement of selectivity over potassium was explained on the basis of tetrahydral binding configuration that was achieved with these receptors.

The group of Compton developed a square wave voltammetric detection method for Vitamin B12 based on the electrocatalytic detection of the $\mathrm{Co}$ (III) center with regeneration of $\mathrm{Co}$ (II).

95 Detection limits of $1 \mathrm{nM}$ were achieved with carbon paste electrodes using 1,2dibromocyclohexane both as binder and electrocatalytic material. The electrode surfaces needed to be renewed after each measurement.

The same research group also developed a highly sensitive electrochemical method for the detection of arsenic(III) at a gold nanoparticle-modified glassy carbon electrode. ${ }^{96}$ The use of either anodic stripping voltammetry or linear sweep voltammetry gave impressive detection limits of $0.01 \mathrm{ppb}$ in $1 \mathrm{M} \mathrm{HCl}$.

The important coenzyme NADH is normally difficult to detect electrochemically because of the limited reversibility of the NADH oxidation reaction. While previous efforts to improve reversibility used electrochemical pretreatments, Palleschi and coworkers successfully employed poly(1,2-diaminobenzene) conducting nanotubule coatings on glassy carbon electrodes. ${ }^{97}$ Amperometric sensor responses remained operationally stable for 2 days. The coating appeared to act as a redox mediator, leading to mild oxidation potentials $(0.55 \mathrm{~V}$ vs. $\mathrm{Ag} / \mathrm{AgCl}$ ), and seemed to inhibit surface fouling.

Zhang and Gorski used carbon nanotubes and redox mediators dispersed into a polymeric matrix for NADH detection, and found a reduction of the overpotential (by $0.3 \mathrm{~V}$ ), a higher sensitivity and faster response times. ${ }^{98}$

Karyakin et al. achieved even further reduction of the required oxidation potential, to just $0 \mathrm{~V}$ at physiological $\mathrm{pH} .{ }^{99}$ This was done by electropolymerization of the prosthetic FAD group that acted as electrocatalyst for NADH oxidation. Operational lifetimes were tested and the modified electrodes remained $90 \%$ responsive after $250 \mathrm{~min}$ and 40 injections of $1 \mathrm{mM} \mathrm{NADH}$ in flow injection analysis. See also the use of heated electrodes to suppress NADH fouling cited above.

\section{Voltammetric Sensors: Analytes of Interest}

Meyerhoff and coworkers reported on an amperometric nitric oxide sensor based on a platinized platinum anode covered with a microporous gas permeable membrane, similar to a Clark oxygen sensor. ${ }^{100}$ The porous membrane effectively discriminated against potentially interfering nitrite ions, and the platinization was responsible for a 10 -fold lower detection limit down to $1 \mathrm{nM}$ ), higher sensitivity and improved stability compared to bare platinum electrodes. This type of sensor was later modified with a thin hydrophilic polyurethane film containing catalytic copper sites that mediated the decomposition of S-nitrosothiols to NO for the fabrication of an electrochemical sensor for S-nitrosothiols. ${ }^{101}$ This type of sensor can possibly be used to assess the ability of blood samples to generate nitric oxide.

In competing work, Liu et al. presented a voltammetric NO sensor, with $1 \mathrm{nM}$ detection limits as well, based on the entrapment of polyoxometalate clusters in a polyelectrolyte matrix deposited onto the electrode. ${ }^{102}$ The clusters appeared to electrocatalyze the reduction of NO, and the polyelectrolyte layers discriminated against nitrite and nitrate, although not as effectively. The group of Schoenfisch explored a variety of sol-gel formulations as NO permeable membranes, with an eye on NO vs. nitrite permeabilities, and found exquisite transport selectivities of more than 4 orders of magnitude after treating the films with $5 \mathrm{~atm}$ NO. ${ }^{103}$ The resulting NO microsensors were fully characterized and the selectivities of the 
sensor were on the order of six orders of magnitude over nitrite, ascorbic acid, uric acid and acetaminophen, with a detection limit of $25 \mathrm{nM}$.

In contrast, Fan et al. reported on an amperometric NO sensor based on a heme protein entrapped in a sodium montmorillonite film deposited on a pyrolitic graphite electrode surface. 104 While similar heme proteins have been used for NO detection before, this group demonstrated the utility under aerobic conditions with a detection limit down to impressive 20 pM. Interferences were tested, but unfortunately only at very dilute concentrations.

Ghoneim and Tawfik reported on the detection of the anticoagulant warfarin in spiked human serum and other samples using square-wave adsorptive cathodic stripping voltammetry at a hanging mercury drop electrode. ${ }^{105}$ The measuring range was found to be relatively narrow for serum samples (1.1 nM to $13 \mathrm{nM})$.

Electrochemical insulin sensors have been reported in the past, but they often lack required selectivity for use in complex samples. Wang and Musameh reported on the use of carbonnanotube modified glassy carbon electrodes in order to accelerate the electrooxidation of insulin, which resulted in a lowering of the required detection potential and a $14 \mathrm{nM}$ detection limit as studied by flow injection analysis. ${ }^{106}$

Selective electrochemical sensors for catecholamines (which include dopamine, see other articles in this review) were designed by Hayashi and coworkers with an interdigitated heteroarray electrode, in view of their application in blood samples. ${ }^{107}$ Indium-tin oxide films were used as the oxidation electrode, mainly because appropriate pretreatment leads to a net negative charge on the electrode surface that gives suppression of the signal to L-ascorbic acid and uric acid. The observed selectivities were not sufficient for direct use in extracellular samples and the authors discussed the possible need for prereactors to further remove interferences.

\section{Electrochemical Gas Sensors}

Capacitive gas sensors are an attractive platform in terms of their fabrication and interrogation, but often suffer from humidity interference since water vapor has a high dielectric constant. Hierlemann and coworkers showed by theory and experiment in a beautiful piece of work that the selectivity of such sensors can be tuned as a function of the sensing film thickness. ${ }^{108}$ Apparently, for each analyte a critical layer thickness must exist where the sensitivity to this analyte vanishes. A difference signal from two layers of different thickness was demonstrated to be virtually independent of humidity fluctuations, for instance. This arrangement also showed less signal drift while maintaining sensitivity to the gases of interest.

Dasgupta and coworkers reported on a microfabricated humidity sensor based on interdigitated rhodium electrodes covered with a Nafion membrane. ${ }^{109}$ The gas sensors showed rapid response times on the order of $50 \mathrm{~ms}$ and long lifetimes $>160 \mathrm{~h}$ ), even when operated under 2 $\mathrm{V}$ d.c. excitation conditions. The authors also showed in the same paper how Au gold electrodes can be made more durable when interrogated at a lower amplitude square wave potential, albeit with slower response times.

Stetter and coworkers reported on an amperometric hydrogen gas sensor and suppression of interferences by carbon monoxide, ammonia and hydrogen sulfide. ${ }^{110}$ This was achieved in a three-electrode configuration using a Pt black electrode, with an FEP membrane mounted at the gas inlet that acted as a hydrogen gas selective filter.

Dutta et al. designed an amperometric sensor to detect hydrocarbons at relatively low temperatures (410-770 K), important for so-called cold start conditions in automotive exhaust 
gas, using a LaGaO3-based Perovskite oxide electrolyte. ${ }^{111}$ The sensors showed good selectitivity against $\mathrm{NO}, \mathrm{NO}_{2}, \mathrm{CO}$ and hydrogen in exhaust, good stability and sensitivity. Hydrogen gas sensors typically operate at elevated temperatures. Lutz et al. went the unusual route to propose a chronoamperometric hydrogenase enzyme-based hydrogen gas sensing system that functions at room temperature. ${ }^{112}$ This system was based on enzyme dissolved in water that also acted as the gas collection medium and still constitutes an assay at this stage. Hydrogen gas was oxidized by the enzyme, and the benzyl viologen acted as electron acceptor and redox mediator.

Meilin Liu and coworkers reported on a porous and nanostructured $\mathrm{SnO}_{2}$ thin film gas sensor with Pt interdigitated electrodes. ${ }^{113}$ The device showed rapid response and recovery times for the detection of ethanol vapor. The response to other gases was not studied, unfortunately. Kolmakov and coworkers enhanced the oxygen and hydrogen gas sensitivity of $\mathrm{SnO} 2$ nanowires, when used as chemiresistor, by plating them with Pd catalyst particles. ${ }^{114}$ The enhancement was explained by the catalytic action of Pd, which was argued predissociate the adsorbing species before the actual chemisorption process. The selectivity of the device was not discussed in this paper.

Haddon and coworkers devised ammonia gas sensors on the basis of single-walled carbon nanotubes functionalized with covalently attached poly(m-aminobenzene sulfonic acid). The sensor was operated as a chemiresistor, with the carbon nanotubes forming a random network between interdigitated electrodes, and improved response and recovery times were observed (on the order of $15 \mathrm{~min}$ ). ${ }^{115}$ The selectivity of the device was not rigorously studied.

In yet another example of nanostructured gas sensors, Ya-Dong $\mathrm{Li}$ and coworkers fabricated hollow sphere WO3 materials with diameters of about $400 \mathrm{~nm}$ with $30-\mathrm{nm}$ shells. ${ }^{116}$ The spheres were evaluated for their gas sensing properties at elevated temperature, and good sensitivities to ethanol, acetone, CS2 and some other organics were found. Response and recover times were on the order of 2 min, making these promising materials.

The group of Compton explored room temperature ionic liquids as a replacement for traditional gas permeable membranes for the construction of amperometric gas sensors. ${ }^{117}$ The authors compared several different cell designs and provided for a theoretical analysis of chronoamperometric transients and expected response times.

\section{Electrochemical Biosensors}

The field of electrochemical biosensors has grown rapidly in the past few years because they may provide fast, simple and low-cost detection capabilities for biological binding events. Research in this field has focused on novel sensing strategies and was supported by a large number of publications about the enhancement of specificity, sensitivity and response time.

\section{Reviews}

Mehrvar and Abdi reviewed recent developments, characteristics, and potential applications of electrochemical biosensors. The authors described the technical importance, performance, techniques, advantages, and disadvantages of biosensors in general and electrochemical biosensors in particular (102 citations). ${ }^{118}$

Lin, Yantasee and Wang reviewed the development of electrochemical biosensors based on carbon nanotubes (CNTs), including their own recent results on this topic and successful applications of CNT-based biosensors ( 88 citations). 119 Merkoci and coworkers also reviewed the topic of electrochemical sensing with carbon nanotubes. The authors discussed the latest advances and future trends in producing, modifying, characterizing and integrating CNTs into 
electrochemical sensing systems, including enzyme-based biosensors (90 citations).120 Wang also reviewed electrochemical biosensors based on nanomaterials, described nanomaterials and nanomaterial-based electrochemical biosensing devices and examined future prospects and challenges (47 citations).121 More specifically, Yanez-Sedeno and Pingarron reviewed electrochemical biosensors based on gold nanoparticles. The authors discussed gold nanoparticle-based electrochemical biosensor designs, enzyme-based electrodes, and immunosensors and DNA sensors (18 citations). 122

Alaejos and Garcia Montelongo reviewed applications of amperometric biosensors with different enzymes and whole cells for the determination of vitamins and amino acids (185 references). ${ }^{123}$ Zhang and Li reviewed recent progress in the development of third-generation electrochemical biosensors based on the direct electron transfer of proteins. The authors specially addressed the topic of protein-film voltammetry (131 citations). 124

The group of Costa-Garcia reviewed recent progress and developments in integrating electrochemical detection methods with enzyme immunoassays (EIAs) (210 references). 125 Cosnier reviewed the different types of affinity biosensors based on electropolymerized polymer films. The author discussed different fabrication methods for those biosensors (123 citations). 126 The group of Hart reviewed the design and fabrication of electrochemical sensors and biosensors based on screen-printed electrodes and their applications (122 citations).127

$\mathrm{Ju}$ and Zhao reviewed the principles of electrochemical biosensors for DNA analysis with emphasis on the enhancement of their selectivity and sensitivity (110 references). ${ }^{128}$ Kerman, Kobayashi and Tamiya reviewed recent trends and challenges in the electrochemical detection of DNA hybridization. The authors also discussed future prospects towards PCR-free DNA chips (102 citations). 129

\section{Enzyme Biosensors Based on Glucose Oxidase and Horseradish Peroxidase}

Enzyme based biosensors have been studied extensively. Research in this field is still focused on the improvement of sensor properties by new sensing approaches. The Glucose Oxidase (GOx) based biosensor for glucose sensing continues to be the primary model system in the development of new sensing materials and methods.

Wang's group reported on a carbon paste based sensor for glucose. ${ }^{130}$ Different from conventional systems, a ferrocene type redox mediator was directly used as pasting liquid. The elimination of the traditional oil binder resulted in a higher sensitivity, a much wider linear response range and better stability, although the response mechanism of the new carbon paste sensors is still under investigation.

Pereira described the amperometric detection of glucose by ion transfer voltammetry (ITIES) based sensors. ${ }^{131}$ Although glucose is a neutral molecule, it can be oxidized to gluconolactone by glucose oxidase. Gluconolactone is further hydrolyzed to gluconic acid and oxygen is reduced to hydrogen peroxide, which provided the protons transferred across the liquid-gel interface, facilitated by an ionophore.

Willner's group also developed a novel method for the electrical contact of glucose oxidase to electrodes by using a supermolecule, rotaxane, electron relay interlocked on a molecular wire. 132 The oxidation of glucose occurred at $-0.4 \mathrm{~V}$, very close to the thermodynamic redox potential of the FAD cofactor.

Another approach to obtain an efficient electron transfer system was developed by Kase and Muguruma. ${ }^{133}$ The authors applied an ultra thin plasma-polymerized film of dimethylaminomethylferrocene as a mediator on a sputtered Au electrode. The amino groups 
of the film allowed one to immobilize a large amount of GOx. The new biosensors can detect glucose over relatively wide range $(1.3 \sim 81 \mathrm{mM})$.

Horseradish peroxidase (HRP) based biosensors are also often studied as a model system. Prieto-Simon et, al. reported metal-dispersed Xerogel-based composite films for preparing electrochemical biosensors. ${ }^{134}$ Iron, copper, cerium and zinc used in the new composites acted as catalysts for the oxidation of hydrogen peroxide. The new composites were used to construct alcohol free sol gel biosensors with GOx and HRP for the detection of glucose and hydrogen peroxide.

Wang's group described a novel approach for enzyme based electrochemical biosensing. ${ }^{135}$ The authors successfully prepared enzyme nanoparticles for the first time. The horseradish peroxidase was crosslinked with glutaraldehyde after desolvation with ethanol. The nanoparticles were then functionalized with thiol groups for attachment on the gold electrode surface. Most of the enzymes preserved their native protein structures and properties after the crosslinking and functionalization procedure. The biosensors exhibited relatively good detection limit for $\mathrm{H} 2 \mathrm{O} 2$ at $100 \mathrm{nM}$ and good reproducibility.

Morrin et al. reported preliminary work on amperometric enzyme biosensors prepared from polyaniline nanoparticles. ${ }^{136}$ The electrodeposition of the polyaniline nanoparticles instead of polyaniline itself on the electrode lead to a smoother, highly ordered conductive nanostructured film. HRP immobilized on the nanoPANI film through electrostatical interaction showed improved deposition characteristics and better signal to noise ratios compared to the direct PANI depositing approach.

\section{Enzyme Biosensors Based on Carbon Nanotubes and Nanoparticles}

The unique electrical and mechanical properties of Carbon Nanotubes (CNTs) make them attractive materials for the construction of electrochemical biosensors. A significant amount of work in the area of enzyme biosensors were related to CNTs and nanomaterials.

Gorski's group studied the integration of CNT with a polysaccharide biopolymer, chitosan, for the fabrication of enzyme biosensors.137 The interactions between the chains and CNT lead to the formation of a stable CNT- chitosan solution and simplified the fabrication procedures for CNT based biosensors. Glucose dehydrogenase was immobilized onto the new biocomposite and the system was able to detect glucose in urine samples. From the same group the electrochemical sensing based on the combination of redox mediation and CNTs was reported. ${ }^{98}$ The authors co-immobilized a redox mediator, the phenothiazine derivatives of Azure dyes (AZU) and CNT in the chitosan biomatrix. The new sensing system amplified the NADH current 35 times and much reduced the response time compared to the system without CNT. The authors explained the CNT enhancement effects by the improvement of electronic and ionic transport capacity of the chitosan-AZU/CNT films.

By using L-amino acid oxidase as the model enzyme, Bachas's group developed a stable biosensor based on CNT aqueous sol-gel composites. ${ }^{138}$ The aqueous sol-gel process provided a mild approach to immobilize the enzyme. Sodium silicate was used as precursor and eliminated the generation of alcohol by-products and enabled the gelation at neutral $\mathrm{pH}$. The new composite materials retained the excellent electrochemical characteristics of CNTs.

Joshi et al. reported that single walled carbon nanotubes (SWCNTs) can be incorporated in redox polymer-enzyme hydrogels for electrochemical biosensing. ${ }^{139}$ The authors investigated two different fabrication procedures. The composites were prepared by incubating glucose oxidase in SWCNTs and crosslinked with the redox polymer for better electrochemical properties. The new sensing approach lead to the increase of current output compared to the 
ones without SWCNT. Hrapovic et al. combined platinum nanoparticles with carbon nanotubes and developed a new approach for the electrochemical detection of glucose.140 Effective deposition of Pt nanoparticles on SWCNT was achieved by using a negatively charged polymer, Nafion, to dissolve and disperse SWCNT. Pt nanoparticles can easily be deposited on the Nafion modified CNT due to charge interactions. Compared to the sensors containing only Pt or CNT, the integration of Pt and CNT lead to improved sensitivity and detection limit.

Different from conventional CNT based biosensors that require a membrane substrate for entrapment or immobilization of the CNT, enzymes and mediators, Lin et al. reported on a glucose biosensor based on CNT nanoelectrode ensembles. ${ }^{141}$ The CNTs were directly grown on the electrically conductive Cr-coated Si substrate, following the attachment of GOx to the tips of the CNTs by using standard the water-soluble coupling agent 1-ethyl-3-(3dimethylaminopropyl)carbodiimide (EDC). The new fabrication allowed them to prepare a mediator free and membrane free biosensor. The new glucose sensors exhibited a response range from 0.08 to $30 \mathrm{mM}$ and a response time of about 20 to $30 \mathrm{~s}$.

In related work to improve the electrical transfer turnover rate in a sensing approach based on the surface reconstitution of apo-proteins on flavin adenine dinucleotide (FAD) functionalized materials, Willner's group reported on the application of orient assembled SWCNTs as nano electrical connectors between glucose oxidase and the electrode surface. ${ }^{142}$ The new sensing scheme eliminated the need for electronic mediators and other membrane materials. The electrons can be effectively transported longer than $150 \mathrm{~nm}$ along the distance of a SWCNT as a nanoconnector, while the transfer rate is controlled by the length of the SWCNT.

The group of Dai studied the electrical conductance of SWCNT field effect transistors upon protein adsorption in view of fabricating label-free detection principles for biomolecules that can be readily miniaturized. ${ }^{143}$ The authors found that non-specific adsorption was rather irreversible, which was alleviated by the use of a number of different surface coatings. Selective label-free immunosensing was demonstrated, albeit with rather drifting signals.

As an alternative to CNTs Yemini et al. reported on a novel peptide nanotube modified electrodes for direct and unmediated biosensing. ${ }^{44}$ The self-assembled diphenylalanine peptide nanotubes attached on the gold electrode surface and were well ordered. By using peroxidase as model enzyme and 4-acetaminophenol as mediator, the authors demonstrated that the peptide nanotube can improve the electrochemical parameters of graphite electrodes.

\section{Other Enzyme Biosensors}

Shan, Mousty and Cosnier described the detection of cyanide with polyphenol oxidase based clay biosensors. ${ }^{145}$ The authors used synthetic Zn-Al layered double hydroxides (LDHs) as matrix to entrap the enzymes. The charge density of layers in LDHs is higher than that of other cationic clays, which makes them a good transducer for the detection of decreased amperometric response due to enzyme inhibition. The positively charged layer also contributed to the preconcentration of the negative cyanide. With the new enzyme immobilization material the detection limit for cyanide was pushed down to $0.1 \mathrm{nM}$.

Zhou et al. reported that the photovoltaic effect can improve the catalytic activity of hemoglobin in a hemoglobin-based biosensor for the detection of hydrogen peroxide. ${ }^{146}$ The hemoglobin as a peroxidase was bioconjugated to titanium dioxide nanoparticles, following the spread of the solution containing the functionalized nanoparticles on a pyrolytic graphite electrode. The photovoltaic effect of $\mathrm{TiO} 2$ nanoparticles resulted in greatly improved enzyme activity under UV light compared to that in the dark. However, the effect was only found for hemoglobin so far and more investigation on the exact reaction mechanism will be necessary. 
Electrochemical determination of nitrate under ambient air without oxygen removal was reported by Nam's group. ${ }^{147}$ The authors used the yeast-originated nitrate reductase immobilized on glassy carbon electrodes and screen-printed carbon paste electrodes. After simple treatment of the sample by adding sodium sulfite as oxygen scavenger, the yeastoriginated nitrate reductase based biosensor can perform accurate and precise in-situ measurements of nitrate without oxygen removal.

Shim's group described the in vivo measurement of glutamate by a glutamate oxidase based microbiosensor. ${ }^{148}$ The enzymes were immobilized on a nano conducting polymer layer electropolymerized on the electrode surface. The microbiosensors can effectively detect glutamate in the concentration range from 0.2 to $100 \mu \mathrm{M}$.

In the detection of dioxygen Rowinski et al. used two different laccases immobilized on the liquid crystalline cubic phase formed with monoolein. ${ }^{149}$ In this water stable liquid crystal matrix the substrates and reaction products can diffuse freely through the water channel inside and provided advantages over many other matrices. The new biosensor can detect lower concentrations of O2 (10-4 M) than Clark-type electrodes.

Schulze, Schmid and Bachmann worked on phosphorothionate biosensors that are less studied because such substrates have a much reduced inhibitory effect toward the corresponding enzyme, acetylcholinesterase.150 Although the traditional approach of activation of the phosphorothionates was followed, the authors used a cytochrome P450 BM-3 mutant as new enzymatic activation reagent, which was more effective for some phosphorothionates than chemical oxidation. Dale's group reported on a microelectrode biosensor for in vivo measurement of ATP in biological tissues. ${ }^{151}$ Amperometric biosensors for ATP are of great promise due to the experimentally simplicity. However, most of ATP biosensors with hexokinase and glucose oxidase suffer from the interference of ambient glucose and can only detect ATP in a low and narrow concentration range (200-300 nM) below the physiological concentration in the nervous system and other tissues. The authors coated the Pt electrode with an ultrathin biolayer containing glycerol kinase and glycerol-3-phosphate oxidase prepared by a new sol-gel deposition method. The sensors exhibited a fast response time and much wider response range $(200 \mathrm{nM} \sim 50 \mu \mathrm{M})$ for ATP, suitable to measure ATP in tissue samples.

Shumyantseva et al. achieved a direct electron exchange between the membrane enzyme CYP2B4 and the electrode by integration of sodium montmorillonite clay nanoparticles and nonionic detergent on the electrode surface as enzyme matrix. ${ }^{152}$ Such biosensors were able to measure various organic substrates such as aminopyrine and benzphetamine related to $\mathrm{NaD}$ (P)H-dependent metabolism.

Detection of L-lactate based on L-lactate-cytochrome c oxidoreductase (Fcb2) biosensors was reported by Smutok et al. ${ }^{153}$ While the type of Fcb2 had advantages over other L-lactate enzymes, the authors further used a new enzyme Fcb2 isolated from yeast Hansenula polymorpha that showed higher stability than other Fcb2 obtained from other sources. The new sensor exhibited sufficient stability, fast response and low working potential.

\section{Enzyme Amplified Immunosensors}

Due to its high sensitivity the electrochemical detection of immunoreactions on the basis of the classic enzyme linked immunosorbent assay is still an extremely popular method. Main research directions are still the developments of new substrates and better immobilization methods in order to improve detection sensitivity of the enzymatic products. For the amperometric detection of immunoreactions, the diffusion of the electroactive probe is essential to the sensitivity of the sensor, which is strongly related to the permeation properties of any polymer used for the immobilization of antibody or antigen. For instance, Cosnier's 
group reported on a new procedure to fabricate immunosensors based on the electrogeneration of a biotinylated copolymer film. ${ }^{154}$ The immunological material was linked to the film and the coelectropolymerization of pyrrole-biotin and pyrrole-lactobionamide monomers formed an anchoring polymeric layer. The copolymer exhibits greater permeability for electroactive species due to the high hydrophilicity of the pyrrole-lactobioamide monomer. The production of electroactive probes was shown to permeate faster to the electrode and provided a shorter response time.

The background current caused by nonspecific adsorption of proteins in enzyme-amplified electrochemical immunoassays is a severe problem that limited the detection sensitivity. Zhang and Heller described a horseradish peroxidase amplified sandwich type immunoassay for the monitoring of IgG. ${ }^{155}$ To suppress the nonspecific adsorption they used two polyanions, poly (acrylic acid-co-maleic acid) and the poly(acrylic acid) to treat the polycationic redox polymermodified screen-printed carbon electrode. Besides electrostatically binding to the polycationic redox polymer surface, these two chosen polyanions can also bind covalently to some residues of avidin through Michael addition reaction at room temperature and neutral $\mathrm{pH}$. The application of the polyanions successfully reduced the nonspecific adsorption-associated noise, lowered the detection limit from $3 \mathrm{ng} / \mathrm{mL}(\sim 20 \mathrm{pM})$ to $\sim 7 \mathrm{pg} / \mathrm{mL}$ ( $\sim 40 \mathrm{fM})$, and also expanded the dynamic concentration range to 4 orders of magnitude.

Jung et al. developed an immunosensor based upon the spontaneous immobilization of biotinylated, functional lipid vesicles (FLVs) on a polymeric resist layer. ${ }^{156}$ Antibodies immobilized on the liposome membrane retained their structure and bioactivity. The strong hydrophilic properties of liposome membrane were also able to prevent nonspecific adsorption of the antibody. However, the individual liposomes tended to disrupt and resulted a decrease of the electrochemical signal. To solve the problem the authors modified the gold electrode by fabrication of $200 \mathrm{~nm}$ (nanoscale) wells in the resist layer utilizing an electron-beam. The assembled FLVs primarily adhered as individual molecules without aggregation or fusion and demonstrated a clearly defined redox activity in electrochemical measurements. Model proteins such as human serum albumin (HSA) and carbonic anhydrase from bovine (CAB) were tested with the new electrochemical immunoassay.

Matsuura et al. developed a highly sensitive surface electrochemical enzyme immunoassay based on the measurement of the activity of acetylcholinesterase. ${ }^{157}$ The main idea was to accumulate the enzymatic reaction product, thiocholine, on the electrode surface via chemisorption/electrochemical desorption cathodically through a one-electron path. The method was highly sensitive and the detection limit for target antigens reached $10 \mathrm{ngL}-1$.

Fernandez-Sanchez et al. successfully integrated a one-step lateral flow immunoassay format and impedance detection with a pH-sensitive polymer layer coated transducer for the sensitive detection of free and total prostate-specific antigen (f-PSA, t-PSA) tumor marker at concentration levels down to $3 \mathrm{ng} / \mathrm{mL} .{ }^{158}$ the authors used low-cost and robust immunostrips as substrate. The nitrocellulose membrane strips loaded with antibodies and antibody-urease enzyme conjugate were coated with a $\mathrm{pH}$-sensitive polymer layer. The $\mathrm{pH}$ sensitive Rohm Pharma polymer undergoes controlled degradation at alkaline $\mathrm{pH}$ caused by the ureasecatalyzed hydrolysis of urea and results in a capacitance change in the system. In order to overcome the drawback of traditional lateral flow immunoassay format, the authors added small storage blisters containing urea solution and developed a true one-step immunosensor.

Halsall and Heineman's group developed a sensitive and miniature immunoassay based on magnetic microbeads and an interdigitated array (IDA) electrode. ${ }^{159}$ It has been demonstrated that the enzymatic reaction on the surface of a microbead can provide short response times on the order of seconds. IDA electrodes were used to further amplify the signal by recycling the 
electrochemically redox-reversible molecules. However, the new method suffered from the nonspecific adsorption of proteins on the microbead surface and lowered the collection efficiency.

Wilson developed an immunoassay based on a novel electrochemically conducting iridium oxide matrix for immobilizing the antibody.160 The new method can maintain the activity of the antibody because the iridium oxide matrix can easily be formed electrochemically under physiological conditions. Such matrix provided a porous three-dimensional hydrous environment for proteins with a high degree of transport for water, protons and ions. Diffusion of electroactive enzyme-generated product was hindered in the matrix. The stability of the antibody may also be improved due to the $3 \mathrm{D}$ hydrous environments in the matrix. In the optimized assay conditions, IrOx sensors exhibited comparable performance with other electrochemical immunosensors. Honda et al. developed a 3D comb electrode for electrochemical immunosensing. ${ }^{161}$ The micro-fabricated 3D electrode was $10 \mu \mathrm{m}$ wide and $30 \mu \mathrm{m}$ tall, with $20 \mu \mathrm{m}$ spacing in between. A single sensor was made up of 30 pairs of anode and cathode electrodes. Such structure efficiently prevented the diffusion of the redox species along to the z-axis of the electrode and improved the trap ratio (nearly 100\%) of the redox species and improved the sensitivity.

\section{Other Immunosensors}

Due to their simplicity, immunosensors based on redox probes without any enzyme amplification attracted interest. Yang et al. described a label-free impedance immunosensor for the rapid detection of Escherichia coli O157:H7 by immobilizing anti-E. coli antibodies onto an indium-tin oxide interdigitated array (IDA) microelectrode. ${ }^{162}$ The authors showed that the immobilization of antibodies and the binding of E. Coli cells to the IDA microelectrode surface increased the electron-transfer resistance, which was directly measured with electrochemical impedance spectroscopy in the presence of $[\mathrm{Fe}(\mathrm{CN}) 6] 3-/ 4-$ as a redox probe. The electron-transfer resistance was correlated with the concentration of E. Coli cells in a range from $10^{5}$ to $10^{8} \mathrm{cfu} / \mathrm{mL}$ with the detection limit of $10^{6} \mathrm{cfu} / \mathrm{mL}$ which was comparable with other label free electrochemical immunoassays.

Mak et al. reported on a novel electrochemical immunoassay based on ferrocene microcrystal as redox-active compound. ${ }^{163}$ The microcrystal core was encapsulated with an ultrathin and porous polymeric capsule conjugated with antibody. The crystal can dissolve immediately and release large amounts of signal generating molecules. The ferrocene microcrystal labeled system exhibited high detection sensitivity and good detection limit.

Electrochemical immunosensing based on new concepts were also reported. Wang's group developed a novel electrochemical immunoassay using DNA as molecular label. ${ }^{164}$ The sandwich immunoassay includes two antibodies linked to magnetic beads and DNAfunctionalized polystyrene spheres. The oligonucleotide strands were released from the beads at alkaline solution and dipurinized by acid. The free nucleobases were electrochemically measured at a graphite electrode after adsorptive accumulation. The new protocol exhibited a high sensitivity, selectivity and miniaturization advantages.

Martin and coworkers made the concept of biological nanopore sensors potentially more robust by utilizing conically shaped pores with a small diameter of $30 \mathrm{~nm}$ in $12-\mu \mathrm{m}$ polymeric membranes decorated with affinity probes. ${ }^{165}$ The ion current across the pore was completely blocked in the presence of suitable target while corresponding experiments with bovine serum albumin showed no appreciable response. Three different detection systems were explored, including biotin/streptavidin, protein-G/immunoglobulin, and anti-ricin/ricin. 
In past years, a number of so-called ion channel sensors were developed, which worked by blocking the access of a redox probe to a metal electrode upon a surface binding event with non-electroactive species. The group of Walder presented a detailed study at the mechanism of charge propagation of such sensors, utilizing seven different proteins in combination with seven different redox markers ions. ${ }^{166}$ They were able to give a number of general statements that will be useful in understanding these devices and in developing new types of sensors.

Wang's group reported on multiplexed immunoassays for protein detection based on different inorganic nanocrystal tracers. ${ }^{167}$ Magnetic beads were used to conjugate the antibodies for target antigens. The bound antigens reacted with a pool of nanocrystal-antibody pairs and were detected by the stripping voltammetric measurement of the corresponding metals. Different protein recognition events yielded different voltammetric peaks which corresponded to different antigens.

\section{Electrochemical DNA Sensors}

Electrochemical techniques remain one of the most attractive methods to detect and identify oligonucleotides due to their high sensitivity, low cost, ease of miniaturization and direct electronic readout. The various detection approaches include direct measurement, conjugation of DNA strand with electroactive reporters, use of soluble electroactive mediator or intercalators, and enzyme labels.

\section{Enzyme labeled DNA Sensors}

Due to their high sensitivity enzyme labeled DNA sensing techniques attracted much attention. Enzyme labeled DNA sensing provides the desired amplification that makes it possible to detect very low target levels.

Hernadez-Santos et al. developed an enzymatic genosensor based on screen-printed carbon electrode. ${ }^{168}$ The electrode surface was coated with streptavidin. The biotinylated oligonucleotides probes were immobilized through streptavidin-biotin interaction. Alkaline phosphatase (AP) was used as the enzyme label. The sensors were able to detect $0.49 \mathrm{fmol}$ of 20-mer oligonucleotide target and discriminate against a three-base mismatch.

To improve the electron transfer efficiency between enzyme reaction and electrode, Xie, Zhang and Gao modified the gold electrode surface with an electrochemical activator bilayer. ${ }^{169}$ After traditional immobilization of ssDNA probes following by hybridization and enzyme labeling, the authors used cationic redox polymers containing osmium-bipyridine complexes coated on the electrode through layer by layer electrostatic self-assembly. The cationic polymer can strongly interact with anionic enzymes and the formation of the anionic-cationic bilayer brought the glucose oxidase in electrical contact with the redox polymer, making the bilayer an electrocatalyst for the oxidization of glucose. The sensor was able to detect nucleic acid molecules amperometrically at femtomolar levels.

The same group reported on an ultrasensitive biosensor for the detection of mRNA. ${ }^{170}$ The new biosensor was based on an enzyme labeled mRNA in the sample and redox polymer bilayer on the electrode surface. The oligonucleotide capture probes were immobilized on the electrode surface by self-assembly. The probes were then hybridized with mRNA labeled with cisplainbiotin conjugates, the glucose oxidase-avidin labels were connected with the labeled RNA through biotin-avidin interaction. A redox polymer was applied to the electrode surface via layer by layer self assembly. The current generated from enzymatic oxidation of glucose was detected and correlated directly to the target gene concentration in the sample solution. The new assay exhibited a 25 fold increase of the sensitivity compared to the sandwich assay. The amount of mRNA that can be detected in the sample was pushed down to nanogram levels. 
Traditionally, one enzyme molecule was conjugated to a single oligonucleotide. Dominguez et al. described an electrochemical DNA sensor using an enzyme with several oligonucleotide sequences. ${ }^{171}$ Each hybridization event resulted in an accumulation of catalytic molecules and a concomitant increase in sensitivity. The GOx was first labeled with several oligonucleotide strands, then followed by the immobilization of DNA probes on the self-assembled multilayers including horseradish peroxidase connected to a redox polymer on the electrode. Such sandwich assay enabled the measurement of a free-label 44-mer oligonucleotide at $1 \mathrm{nM}$ concentration. Wang's group reported on a novel method to dramatically amplify enzyme based DNA sensing by using carbon nanotubes. ${ }^{172}$ In the new sensing scheme, the DNA duplex acted as connectors between microbeads and CNTs. The CNT loaded with enzymes linked to the magnetic microbeads through the interaction of complementary oligonucleotides. Without the recognition event the CNT cannot attach to the particles and is removed during the magnetic separation. The CNTs function as carriers for enzyme tags and the enzyme reaction products were also accumulated in the CNTs. The coupling of enzyme tagged CNTs provided a better detection limit than single-enzyme labels and a conventional glassy carbon transducer.

\section{DNA Sensors Based on Other Labels}

Enzyme-less DNA sensors based on indirect measurements of intercalators commonly use metal complexes such as daunomycin or methylene blue as redox indicators.

Liu and Anzai developed a poly(4-vinylpyridine) derivatives containing redox active osmium complexes in the side chains as a hybridization indicator for electrochemical DNA sensors.

173 The polymeric indicator remains the properties of the osmium complex monomer and exhibited 1000 times higher sensitivity than the monomer analogue due to the polymeric effect. The redox potential of the polymeric indicator was also found to be much lower than that reported for the monomeric analogue. The new polymeric redox indicator can also be easily removed from the sensor surface and enabled the repeated use of the sensors.

Rusling's group developed a voltammetric sensor for oxidized DNA using films containing two Osmium and Ruthenium metallopolymers. ${ }^{174}$ The films were assembled layer by layer on the electrode surface and exhibited two different redox potentials corresponding to electroactive $\mathrm{Os}^{3+} / \mathrm{Os}^{2+}$ and $\mathrm{Ru}^{3+} / \mathrm{Ru}^{2+}$ centers that can catalyze the oxidation of 8-oxoguanine and guanine respectively at well-separated potentials. Therefore, the new sensors can selectively detect oxidized DNA by monitoring the catalytic Os square wave voltammetry peak mainly selective for 8-oxoguanine and other oxidized nucleobases from the Ru peak.

Kim et al. reported on a new electrochemical DNA sensor with highly selective discrimination of single base mismatches without post-hybridization washing. ${ }^{175}$ The authors used double stranded DNA as probes and a competitive hybridization replacement sensing approach. The double stranded probe attached on the electrode surface was prepared by hybridization of capture DNA and signaling DNA. Ferrocene-conjugated DNA was coupled with signaling DNA strand. Under thermal stringency a perfectly matched target DNA displaced the capture DNA to make a more stable duplex, and at the same time the signaling DNA is removed from the electrode surface. The single-base-mismatched target DNA displaced the capture DNA much slower. King's group described a novel detection method for RNA. ${ }^{176}$ The two electrochemically distinct, enzyme-compatible ribonucleoside triphosphates labeled with ferrocene and anthraquinone were incorporated into RNA transcripts and detected specifically at a DNA-functionalized electrode.

Fojta and co-workers reported on a new electrochemical detection of the length of the triplet expansion based on multiple hybridization of the DNA repetitive sequence at magnetic beads with a short biotin-labeled reporter probe (RP) complementary to the triplet repeats. ${ }^{177}$ The reporter probe is detected via an enzyme-linked electrochemical assay with converting 
electroinactive 1-naphthyl phosphate to electroactive 1-naphthol. Osmium tetroxide, 2,2'bipyridine (Os,bipy) was introduced as electroactive labels in tDNA. The length of the triplet expansion is calculated from the ratio of the intensities of electrochemical signals of hybridized RP/tDNA-Os,bipy.

Contrary to most DNA sensors based on conducting polymers with anion exchange properties, Reisberg et al. reported on a novel DNA sensor constructed with a cation exchange conducting polymer. ${ }^{178}$ The polymers contained a cation-exchange redox group, quinine, as immobilized redox-active label. Such properties lead to a novel "signal on" detection approach which enabled the detection of various probe and target lengths (10-30 bp) and single mismatch discrimination. The paper also showed that one probe strand can be used to address several shorter targets.

Oligonucleotide modified electroactive polymers have been used in DNA biosensing. However, such polymers can lead to a strong electrical background due to their insolubility in water and the electrical signal is usually decreases after hybridization. Le Floch et al. introduced a new sensing approach using neutral peptide nucleic acid as capture probes and an electroactive, cationic, water-soluble polythiophene as transducer. ${ }^{179}$ The electrostatic interaction with the transducer occurred only when the neutral probes hybridized with negatively charged complementary target stands.

Peng et al. reported on the label-free electrochemical detection of DNA based on new functionalized conducting copolymer, poly[pyrrole-co-4-(3-pyrrolyl)butanoic acid]. ${ }^{180}$ The DNA probes were covalently attached to the surface of the conducing polymer. The hybridization of complementary oligonucleotides with the probes lead to a significant and reproducible signal compared to non-complementary oligonucleotides.

The application of nanoparticles for DNA sensing has attracted the attention of several research groups. Pumera et al. described a gold nanoparticle based biosensor for direct detection of DNA. ${ }^{181}$ The biotinylated probe DNA strands were immobilized on streptavidin coated magnetic beads. The target DNA marked with Au67 quantum dots in the ratio 1:1 hybridized with probe DNA, which prevented the formation of an interconnected three-dimensional network of Au-DNA duplex-paramagnetic beads as previously developed nanoparticle DNA assays. The hybridized magnetic beads were accumulated on the surface of a magnetic electrode and enable the magnetically trigged direct electrochemical detection of gold quantum dot tracers without prior chemical dissolution of the metal quantum dots.

Kerman et al. reported on the detection with single-stranded DNA binding protein modified gold nanoparticles. ${ }^{182}$ The microbeads with immobilized probe DNA strand were accumulated on a carbon paste electrode, while Au nanoparticles were modified with the same single stranded probe and then coated with binding proteins. This approach reduced the nonspecific binding of Au nanoparticles. Changes in the Au oxidation signal was monitored upon binding of Au tagged Escherichia coli single stranded binding protein (SSB) to probe and hybrid on the electrode surface. The amplified oxidation signal of Au nanoparticles provided a detection limit of 2.17 pM target DNA.

\section{Label-Free Electrochemical DNA Detection}

A new transducing material, rigid carbon composites, was reported by Erdem et al. for DNA sensors. ${ }^{183}$ The extent of hybridization was detected with differential pulse voltammetry using the oxidation signal of guanine originating from the target. The composites prepared by mixing graphite powder and epoxy resin had an uneven surface allowing oligonucleotides to be absorbed easily. The oxidation potentials were much lower when such graphite-epoxy composites was used. Free guanine base was oxidized at $+0.35 \mathrm{~V}$ while adenine oxidation 
occurred at $+0.63 \mathrm{~V}$ (vs $\mathrm{Ag} / \mathrm{AgCl}$ ). Cytosine and inosine free bases showed no peaks within the experimental potential range. The oxidation of DNA guanine moieties occurred at a potential of $+0.55 \mathrm{~V}$ while DNA adenine bases were oxidized at $+0.85 \mathrm{~V}$. DNA hybridization has been determined in a target concentration of $10 \mathrm{mg} / \mathrm{ml}$ in $15 \mathrm{~min}$ hybridization time.

Based on the unique binding properties between Escherichia coli single stranded binding protein (SSB) and single-stranded DNA (ssDNA), the Kerman et al. reported on a simplified DNA sensors based on the intrinsic oxidation signals of nucleic acids and proteins on a singlewalled carbon nanotube (SWCNT)-modified screen-printed carbon electrode (SPE). ${ }^{184}$ The voltammetric signal from guanine oxidation significantly decreased upon binding of SSB to single-stranded probes, while oxidation of the tyrosine (Tyr) and tryptophan (Trp) residues of the SSB protein increased upon binding of the SSB protein to ssDNA and ss-oligonucleotides. After the hybridization, SSB did not bind to the double helix form, and the guanine signal could be observed along with the disappearance of the oxidation signal of the protein. With the amplification of the guanine and protein oxidation signals by SWCNTs the detection limit of $0.15 \mathrm{mg} / \mathrm{ml}$ target DNA was achieved.

Kerman et al. also described the label-free electrochemical detection of DNA based on the direct attachment of adenine probes to the side-wall and end of functionalized multi-walled carbon nanotubes. ${ }^{185}$ The MWNTs were attached onto the carbon paste electrode surface modified with thymine probes by hybridization between adenine and thymine. The combination of side-wall and end functionalization of MWNT showed enhancement of the guanine oxidation signal in the direct measurement compared to the ones from only endmodified MWNT. This approach resulted in a detection limit down to $10 \mathrm{pg} / \mathrm{mL}$ and could discriminate against single-base mismatches and noncomplementary DNA.

Cai et al. reported on the direct impedance detection of DNA hybridization on a silicon surface. ${ }^{186} \mathrm{~N}$ - and p-type silicon surfaces were chemically modified with amino groups and covalently linked with thiol-modified oligonucleotides probes. The hybridization of target complementary oligonucleotides sequence in the sample solution with the probes resulted in significant changes in both real and imaginary components of the electrical impedance, while exposure to DNA with non-complementary sequences generated negligible responses. Field-effect transistors (FETs) were also explored for the label-free detection of oligonucleotides. DNA molecules are negatively charged in aqueous solution, and the detection at a genetic FET appears to be based on a charge-density change at the gate surface induced by hybridization. The groups of Ingebrandt, Shin and Miyahara independently developed FET-type DNA biosensors. In all cases the probe DNA strands were directly immobilized on the gate surface by chemical modification. Ingebrandt et al. used FET sensors with $\mathrm{SiO} 2$ gate oxide and oppositely charged polyelectrolytes (PAH and PSS). ${ }^{187}$ The sensor enabled the detection of natural 19 base-pair sequences hybridization. However, the sensors suffered from long hybridization times. Shin's group chose a p-channel MOSFET because the native charge of the phosphate groups in DNA determines the effective gate potential.188 Thiol modified Au was used as gate metal for the immobilization of DNA probes. Sakata and Miyahara developed a genetic FET sensor with probe DNA directly attached on the modified Si3N4 surface.189 Different from other approaches, the authors used DNA binders as charged species for doubled-stranded DNA after hybridization, which enabled the detection of single-based mismatch of target DNA.

Yang and co-workers detected DNA with diamond thin film modified electrodes. ${ }^{190}$ The thiol functionalized probe was linked to the diamond surface after the surface was photochemically treated with 10-aminodec-1-one. The impedance change induced by DNA hybridization was monitored without the need for any label. 
Gu et al. also developed an impedimetric diamond-based sensor for sensing DNA

hybridization. ${ }^{191}$ Different from the wet chemical processing steps reported before, the authors used a simple one step electropolymerization to introduce a self -terminating ultrathin layer of polyaniline/polyacrylic copolymer film containing a high density of functional groups for linking with DNA probes on the boron-doped diamond surface. The polymer-modified boron doped diamond electrode was robust and shows no detectable nonspecific adsorption, with good selectivity between the complementary DNA targets and one-base pair mismatched targets. The detection limit was reported as $2 \times 10^{-8} \mathrm{M}$ at $1000 \mathrm{~Hz}$.

Electrochemical impedance spectroscopy was also used by Long et al. for the detection of single-nucleotide mismatches. ${ }^{192}$ The detection was based on the change of the resistance to charge transfer (RCT) before and after normal duplex DNA was converted to a metalated DNA. The RCT value difference between B- and M-DNA enabled a reliable measurement of single nucleotide mismatches in ideal conditions. A 100 pM detection limit was achieved with the new sensing method.

\section{DNA (aptamer) based sensors for other analytes}

$\mathrm{Xu}$ et al. used aptamer based array electrodes for the detection of proteins. ${ }^{193}$ The aptamers reportedly showed a stronger and more selective affinity for protein targets compared to antibodies. To increase the binding efficiency for proteins, a hybrid modified layer containing aptamers and cysteamine was fabricated on the gold electrode surface. The impedance spectroscopic detection also provided high sensitivity and better selectivity. The method was able detect human IgE in the range of $2.5-100 \mathrm{nM}$. A detection limit of $5 \mathrm{fmol}$ in a $50 \mathrm{~mL}$ sample was achieved with an average relative standard deviation of less than $10 \%$.

Wang's group also reported on an aptamer-based biosensor for the detection of proteins via Faradaic Impedance Spectroscopy (FIS),194 which is sensitive to the change in surface charge upon binding. The formation of such bioaffinity complexes commonly leads to an insulating layer that retards the interfacial electron transfer kinetics between the redox probe and the electrode and increases the electron-transfer resistance. Contrary to impedance-based immunoassays, the aptamer-protein interaction lead to a decrease (rather than the common increase) in the electron transfer resistance. Without target protein the negatively-charged [Fe (CN)6]32/42 marker was repelled from the surface and its redox reaction was found to be hindered. When the protein binds to the aptamer probe, the $[\mathrm{Fe}(\mathrm{CN}) 6] 32 / 42$ marker was attracted to the surface and the resistance to electron transfer was found to decrease. Bang, Cho and Kim used a beacon aptamer-based biosensor for the detection of thrombin.195 The beacon aptamer modified with a linker containing a primary aliphatic amine was attached to gold electrode surface. Methylene blue (MB) was intercalated into the beacon sequence, and used as an electrochemical marker. The intercalated MB could be released when the immobilized beacon aptamer encountered thrombin and was conformationally changed, which resulted in a decrease in electrical current intensity in the voltammogram. The aptamer sensor exhibited a linear range between 0 and $50.8 \mathrm{nM}$ of thrombin and a detection limit of $11 \mathrm{nM}$.

In the same year, the group of Plaxco described a similar system for the detection of thrombin. ${ }^{196}$ Here, the methylene blue label was covalently attached to one of the DNA strands. Upon interaction of thrombin with the other strand the label became detectable by alternating current voltammetry, forming a pseudo-reagentless detection system for thrombin down to $3 \mathrm{nM}$. Bovin serum albumin, as a rough selectivity test, did not induce a response at $300 \mathrm{nM}$ levels.

Babkina et al. determined auto-antibodies using DNA interaction with a Pt(II) complex. ${ }^{197}$ The denatured DNA was immobilized on cellulose nitrate film coated on the electrode. Pt complexes in the aqueous solution acted as the electrochemical probe that can interact with denatured DNA and form stable complexes. After the immunoreaction of auto-antibodies, the 
current of catalytic hydrogen evolution in the presence of the complex was monitored. The measuring range for auto-antibodies was reported as 10-10 to 10-8 M

Babkina and Ulakhovich also reported on the amperometric detection for transition metals with DNA based sensors. ${ }^{198}$ Different metals have different complexation abilities with single stranded DNA, double stranded DNA and immobilized single stranded DNA. The method could detect the metals $\mathrm{Cu}, \mathrm{Pb}, \mathrm{Fe}$ at $10^{-11}, 10^{-10}, 10^{-9} \mathrm{M}$. However, a biospecific preconcentration step was required for this method.

Girault's group described a DNA modified electrode sensor for the detection of antioxidants using a $\mathrm{TiO}_{2} /$ ITO modified electrode. ${ }^{199}$ Double stranded DNA was efficiently immobilized on the $\mathrm{TiO}_{2}$ film. The dsDNA was oxidized through photogenerated hydroxyl radicals. The damage of the DNA by reactive oxygen species was detected by adding methylene blue as an intercalator redox probe and by monitoring the associated reduction current.

Li et al. reported on the impedance sensing of DNA binding drugs using a gold electrode containing gold nanoparticles immobilized with DNA. ${ }^{200}$ The interaction of the DNA binding drugs with immobilized DNA on the electrode surface was reported to cause a change in the capacitance and in the interfacial electron resistance, by reducing the active area of the electrode or by preventing the redox species from approaching the electrode. Two different minor groove binders were compared in this study.

\section{Conclusions}

Electrochemical sensor research is a diverse, healthy field that enjoys a significant level of activity in numerous countries all over the world. Some key areas of special interest can be identified here. Research on potentiometric sensors is to a large part still driven by the discovery of a few years ago that these devices can reach detection limits that are orders of magnitude lower than previously thought possible. In the past two years, efforts have focused on making these devices more robust, and to avoid the influence of the inner solution on the detection limit as much as possible. This was achieved with solid contact formulations on the basis of conducting polymers and by choosing long diffusion paths between the inner solution and sample. A new, fresh approach to ion-selective electrodes was introduced by the appearance of fluorous membrane phases, which have the potential of significant impact by offering a class of materials that will be more inert towards biological samples and offer unprecendented selectivity ranges. Potentiometric sensors operated in a kinetic mode were found to be sensitive to localized surface atttachment processes, opening up new possibilities. Conducting polymers, despite having appeared in ion-selective electrode research many years ago, overall underwent a strong resurgence in the past two years. Research on reference electrodes was, as in the past, rather limited in quantity, but some papers suggested new concepts to achieve liquid-junction free systems, or established ones on the basis of new materials.

The field of ion transfer voltammetry saw increased activity and appears to develop rapidly to a practical sensor platform, away from a tool for a select few to solve fundamental problems. Some key advances in this field include the concept of calibration-free, coulometric ion detectors, and ion transfer voltammetric as well as pulsed chronopotentiometric sensors for polyionic analytes. With voltammetric sensors, the application of molecularly imprinted polymers as artificial and potentially more durable receptor materials is gaining popularity. Voltammetric sensors now also benefit more from chemometric tools, including Fouriertransformations, to extract useful data and to enhance sensor selectivity. A new approach to modify the electrochemical waveform has also been proposed to effectively deal with charging currents for voltammetric sensors, and this may have important implications for the design of low-detection limit sensors of this type. Other innovative approaches, such as localized heating 
of the electrode, offer added dimensionality and have been shown to reduce surface fouling in some cases. Also of note is a new approach to suppress undesired humidity responses with capacitive gas sensors on the basis of calculated sensing film thickness variations.

While glucose sensors are well established and commercially available, research has continued to improve on its design, including the use of new binders in carbon paste electrodes, principles of ion transfer voltammetry, and the use of nanoparticles and molecular wiring. Nanoparticles in particular were an extremely popular theme in biosensor research. Principal motivations were their use as electrochemically readable labels, the possibility of effective blending with other sensing film components, their high effective surface area that result in higher sensitivity, and their use for long distance electrical connectivity in the form of nanowires. Unfortunately, the quest for improved sensitivity was sometimes at the expense of the critical evaluation of other sensing parameters such as selectivity, especially in the gas sensor community. Research also focused on new membrane materials, including mesoporous materials, numerous types of sol-gel materials that sometimes show impressive permeation selectivities, and electrochemically polymerized films with selective transport characteristics. The quest for electrochemical detection of oligonucleotides with very low detection limits has intensified, and the number of explored variations have been enormous, although most have centered on common themes borrowed from electrochemical immunoassay approaches. A variety of enzyme labels were explored, giving the possibility for effective amplification. The attachment of numerous enzymes on a single carbon nanotube label provided for enormous signal enhancement, for instance, although non-specific binding onto the label material may be a problem. Label-free DNA detection was also an important theme. Some of the approaches involved the irreversible destruction of the measured DNA and electrochemical measurement of detached nucleobases, sometimes in combination with other signals. Field effect transistors were found to be able to detect DNA hybridization reactions without requiring any label, although the results were still quite preliminary. Impedance analysis was also found to be useful. Aptamers, DNA-based recognition elements that function in analogy to antibodies, were further explored in biosensor research. Of note is work that used an electrochemical beacon aptamer for the detection of thrombin, where the label was only allowed access to the electrode surface upon binding to the target.

The enormous activity in electrochemical sensor research is a reflection of the importance of the field, and the power and convenience that electrochemistry offers in detecting and triggering binding events. There is a good quantity of excellent, high quality sensor research going on. Unfortunately, there are also numerous published papers that lack scientific rigor, where important characteristics such as selectivity are either not mentioned or not sufficiently studied. There is also a tendency of decreasing increments of novelty in the literature, which likely reflects the ever increasing pressure to publish, but which is negatively affecting the quality of published work. Of course, science must look forward for innovation, and the excitement one feels in many areas of chemical sensing is a key driving force for eventual success. Nonetheless, this field is rather old and rooted, and researchers bear an important responsibility in also connecting with past work and to build on the level of excellence that came before us. Researchers should also keep in mind that chemical sensors are, at the end of the day, meant to be used in a real-world sample environment that pose clear demands on selectivity, sensitivity, detection limits and ruggedness.

\section{Acknowledgments}

The authors would like to thank the National Institutes of Health and the National Science Foundation for support of their electrochemical sensor research. 


\section{Biographies}

Eric Bakker is a professor of chemistry at Purdue University. He received his Ph.D. with Wilhelm Simon at the Swiss Federal Institute of Technology in Zurich, Switzerland, in 1993. After two years of postdoctoral work at the University of Michigan, Ann Arbor, and 10 years as a faculty member at Auburn University he moved to his current position in 2005. His research interests are the development and understanding of electrochemical sensors based on molecular recognition principles and the development of microsphere fluorescent sensing arrays for a variety of analytes.

Yu Qin is an associate professor in the department of Chemistry at Renmin University of China. She earned her Ph.D. in analytical chemistry with Eric Bakker at Auburn University following undergraduate studies of Chemistry at Nanjing University in China. She continued her postdoctoral studies with Eric Bakker before she joined the faculty at Renmin University of China in 2005. Her research interests include the design and synthesis of molecular probes and applications in electrochemical and optical sensors.

\section{References}

1. Wroblewski W, Dybko A, Malinowska E, Brzozka Z. Talanta 2004;63:33-39. [PubMed: 18969402]

2. Shim JH, Jeong IS, Lee MH, Hong HP, On JH, Kim KS, Kim H-S, Kim BH, Cha GS, Nam H. Talanta 2004;63:61-71. [PubMed: 18969404]

3. Macca C. Anal. Chim. Acta 2004;512:183-190.

4. Bakker E, Buhlmann P, Pretsch E. Talanta 2004;63:3-20. [PubMed: 18969400]

5. Bakker E, Pretsch E. TrAC, Trends Anal. Chem 2005;24:199-207.

6. Muslinkina L, Pretsch E. Chem. Commun 2004:1218-1219.

7. Xu Y, De Marco R, Shvarev A, Bakker E. Chem. Commun 2005:3074-3076.

8. Tompa K, Birbaum K, Malon A, Vigassy T, Bakker E, Pretsch E. Anal. Chem 2005;77:7801-7809. [PubMed: 16316191]

9. Nevins Buchanan SA, Balogh LP, Meyerhoff ME. Anal. Chem 2004;76:1474-1482. [PubMed: 14987106]

10. Wang K, Xu J-J, Tang K-S, Chen H-Y. Talanta 2005;67:798-805. [PubMed: 18970242]

11. Egorov V, Rakhman'ko E, Okaev E, Nazarov V, Pomelyenok E, Pavlova T. Electroanalysis 2004;16:1459-1462.

12. Alaviuhkola T, Bobacka J, Nissinen M, Rissanen K, Ivaska A, Pursiainen J. J. Chem. Europ. J 2005;11:2071-2080.

13. Gorski L, Saniewska A, Parzuchowski P, Meyerhoff ME, Malinowska E. Anal. Chim. Acta 2005;551:37-44.

14. Hattori H, Hoshino M, Wakii T, Yuchi A. Anal. Chem 2004;76:5056-5062. [PubMed: 15373442]

15. Qin Y, Bakker E. Anal. Chem 2004;76:4379-4386. [PubMed: 15283576]

16. Ortuno JA, Exposito R, Sanchez-Pedreno C, Albero MI, Espinosa A. Anal. Chim. Acta 2004;525:231237.

17. Le Goff T, Braven J, Ebdon L, Scholefield D. Anal. Chim. Acta 2004;510:175-182.

18. Boswell PG, Buehlmann P. J. Am. Chem. Soc 2005;127:8958-8959. [PubMed: 15969566]

19. Lee BH, Shim Y-B, Park SB. Anal. Chem 2004;76:6150-6155. [PubMed: 15481966]

20. Marxer SM, Schoenfisch MH. Anal. Chem 2005;77:848-853. [PubMed: 15679353]

21. Shin JH, Lee HL, Cho SH, Ha J, Nam H, Cha GS. Anal. Chem 2004;76:4217-4222. [PubMed: 15253666]

22. Broncova G, Shishkanova TV, Matejka P, Volf R, Kral V. Anal. Chim. Acta 2004;511:197-205.

23. Lindfors T, Ivaska A. Anal. Chem 2004;76:4387-4394. [PubMed: 15283577]

24. Sutter J, Lindner E, Gyurcsanyi Robert E, Pretsch E. Anal. Bioanal. Chem 2004;380:7-14. [PubMed: 15309365] 
25. Sjoberg-Eerola P, Bobacka J, Sokalski T, Mieczkowski J, Ivaska A, Lewenstam A. Electroanalysis 2004;16:379-385.

26. Vazquez M, Danielsson P, Bobacka J, Lewenstam A, Ivaska A. Sens. Actuators, B 2004;B97:182189.

27. Grygolowicz-Pawlak E, Wygladacz K, Sek S, Bilewicz R, Brzozka Z, Malinowska E. Sens. Actuators, B 2005;B111-B112:310-316.

28. Chaniotakis NA, Alifragis Y, Konstantinidis G, Georgakilas A. Anal. Chem 2004;76:5552-5556. [PubMed: 15362920]

29. Konopka A, Sokalski T, Michalska A, Lewenstam A, Maj-Zurawska M. Anal. Chem 2004;76:64106418. [PubMed: 15516135]

30. Michalska A, Maksymiuk K. Talanta 2004;63:109-117. [PubMed: 18969408]

31. Sutter J, Radu A, Peper S, Bakker E, Pretsch E. Anal. Chim. Acta 2004;523:53-59.

32. Michalska AJ, Appaih-Kusi C, Heng LY, Walkiewicz S, Hall EAH. Anal. Chem 2004;76:2031-2039. [PubMed: 15053668]

33. Puntener M, Vigassy T, Baier E, Ceresa A, Pretsch E. Anal. Chim. Acta 2004;503:187-194.

34. Vigassy T, Huber Christian G, Wintringer R, Pretsch E. Anal. Chem 2005;77:3966-3970. [PubMed: 15987098]

35. Radu A, Meir AJ, Bakker E. Anal. Chem 2004;76:6402-6409. [PubMed: 15516134]

36. Kim BH, Hong HP, Cho KT, On JH, Jun YM, Jeong IS, Cha GS, Nam H. Talanta 2005;66:794-804. [PubMed: 18970054]

37. Szczygelska-Tao J, Biernat JF, Gorski L, Malinowska E. J. Inclusion Phenom. Macrocyclic Chem 2004;49:167-171.

38. Gyurcsanyi RE, Lindner E. Anal. Chem 2005;77:2132-2139. [PubMed: 15801747]

39. Langmaier J, Lindner E. Anal. Chim. Acta 2005;543:156-166.

40. Long R, Bakker E. Anal. Chim. Acta 2004;511:91-95.

41. Heng LY, Toth K, Hall EAH. Talanta 2004;63:73-87. [PubMed: 18969405]

42. Phillips KN, Lantz C, Buhlmann P. Electroanalysis 2005;17:2019-2025.

43. Pejcic B, De Marco R. Appl. Surf. Sci 2004;228:378-400.

44. Blaz T, Migdalski J, Lewenstam A. Analyst 2005;130:637-643. [PubMed: 15852131]

45. Kisiel A, Marcisz H, Michalska A, Maksymiuk K. Analyst 2005;130:1655-1662. [PubMed: 16284665]

46. Ha J, Martin SM, Jeon Y, Yoon IJ, Brown RB, Nam H, Cha GS. Anal. Chim. Acta 2005;549:59-66.

47. Ciobanu M, Wilburn JP, Lowy DA. Electroanalysis 2004;16:1351-1358.

48. Kunimatsu M, Qiao H, Okada T. J. Electrochem. Soc 2005;152:E161-E166.

49. Bond AM, Duffy NW, Guo S-X, Zhang J, Elton D. Anal. Chem 2005;77:186A-195A.

50. Umezawa Y, Roki H. Anal. Chem 2004;76:320A-326A.

51. Amatore C, Maisonhaute E. Anal. Chem 2005;77:303A-311A.

52. Niwa O. Bull. Chem. Soc. Jpn 2005;78:555-571.

53. Economou A. TrAC, Trends Anal. Chem 2005;24:334-340.

54. Walcarius A. C. R. Chim 2005;8:693-712.

55. Zen J-M, Kumar AS. Anal. Chem 2004;76:205A-211A.

56. Blanco-Lopez MC, Gutierrez-Fernandez S, Lobo-Castanon MJ, Miranda-Ordieres AJ, Tunon-Blanco

P. Anal. Bioanal. Chem 2004;378:1922-1928. [PubMed: 15064901]

57. Town RM, Van Leeuwen HP. Electroanalysis 2004;16:458-471.

58. Hanrahan G, Patil DG, Wang J. J. Environ. Monit 2004;6:657-664. [PubMed: 15292947]

59. Trojanowicz M, Wcislo M. Anal. Lett 2005;38:523-547.

60. Samec Z, Samcova E, Girault HH. Talanta 2004;63:21-32. [PubMed: 18969401]

61. Knake R, Jacquinot P, Hodgson AWE, Hauser PC. Anal. Chim. Acta 2005;549:1-9.

62. Yoshizumi A, Uehara A, Kasuno M, Kitatsuji Y, Yoshida Z, Kihara S. J. Electroanal. Chem 2005;581:275-283. 
63. Zhan D, Mao S, Zhao Q, Chen Z, Hu H, Jing P, Zhang M, Zhu Z, Shao Y. Anal. Chem 2004;76:41284136. [PubMed: 15253653]

64. Yuan Y, Amemiya S. Anal. Chem 2004;76:6877-6886. [PubMed: 15571336]

65. Guo J, Yuan Y, Amemiya S. Anal. Chem 2005;77:5711-5719. [PubMed: 16131086]

66. Shvarev A, Bakker E. Anal. Chem 2005;77:5221-5228. [PubMed: 16097762]

67. Makarychev-Mikhailov S, Shvarev A, Bakker E. J. Am. Chem. Soc 2004;126:10548-10549.

[PubMed: 15327306]

68. Sutter J, Morf WE, De Rooij NF, Pretsch E. J. Electroanal. Chem 2004;571:27-35.

69. Yoo J-S, Park S-M. Anal. Chem 2005;77:3694-3699. [PubMed: 15924407]

70. Shtoyko T, Richardson JN, Seliskar CJ, Heineman WR. Electrochim. Acta 2005;50:3191-3199.

71. Maghasi AT, Conklin SD, Shtoyko T, Piruska A, Richardson JN, Seliskar CJ, Heineman WR. Anal. Chem 2004;76:1458-1465. [PubMed: 14987104]

72. Salauen P, Buffle J. Anal. Chem 2004;76:31-39.

73. Wiyaratn W, Somasundrum M, Surareungchai W. Anal. Chem 2004;76:859-862. [PubMed: 14750886]

74. Wiyaratn W, Hrapovic S, Liu Y, Surareungchai W, Luong JHT. Anal. Chem 2005;77:5742-5749. [PubMed: 16131090]

75. Moreno L, Merkoci A, Alegret S, Hernandez-Cassou S, Saurina J. Anal. Chim. Acta 2004;507:247253.

76. Heien MLAV, Johnson MA, Wightman RM. Anal. Chim 2004;76:5697-5704.

77. Zhang J, Guo S-X, Bond AM, Marken F. Anal. Chim 2004;76:3619-3629.

78. Lau C, Flechsig G-U, Gruendler P, Wang J. Anal. Chim. Acta 2005;554:74-78.

79. Zen J-M, Hsu C-T, Hsu Y-L, Sue J-W, Conte ED. Anal. Chim 2004;76:4251-4255.

80. Clark EA, Fritsch I. Anal. Chim 2004;76:2415-2418.

81. Simm AO, Banks CE, Compton RG. Anal. Chim 2004;76:5051-5055.

82. Weber G, Messerschmidt J. Anal. Chim. Acta 2005;545:166-172.

83. Marx S, Zaltsman A, Turyan I, Mandler D. Anal. Chim 2004;76:120-126.

84. Huan S, Chu H, Jiao C, Zeng G, Huang G, Shen G, Yu R. Anal. Chim. Acta 2004;506:31-39.

85. Pogorelova SP, Kharitonov AB, Willner I, Sukenik CN, Pizem H, Bayer T. Anal. Chim. Acta 2004;504:113-122.

86. Kitade T, Kitamura K, Konishi T, Takegami S, Okuno T, Ishikawa M, Wakabayashi M, Nishikawa K, Muramatsu Y. Anal. Chim 2004;76:6802-6807.

87. Liang H-J, Ling T-R, Rick JF, Chou T-C. Anal. Chim. Acta 2005;542:83-89.

88. Dineiro Y, Menendez MI, Blanco-Lopez MC, Lobo-Castanon MJ, Miranda-Ordieres AJ, TunonBlanco P. Anal. Chim 2005;77:6741-6746.

89. Aldakov D, Anzenbacher P. J. Am. Chem. Soc 2004;126:4752-4753. [PubMed: 15080659]

90. Lee J, Park S-M. Anal. Chem. Acta 2005;545:27-32.

91. Miyahara T, Kurihara K. J. Am. Chem. Soc 2004;126:5684-5685. [PubMed: 15125658]

92. Sonthalia P, McGaw E, Show Y, Swain GM. Anal. Chim. Acta 2004;522:35-44.

93. Yantasee W, Lin Y, Fryxell GE, Busche BJ. Anal. Chim. Acta 2004;502:207-212.

94. Rahman MA, Kwon N-H, Won M-S, Hyun M-H, Shim Y-B. Anal. Chim 2004;76:3660-3665.

95. Tomcik P, Banks CE, Davies TJ, Compton RG. Anal. Chem 2004;76:161-165. [PubMed: 14697046]

96. Dai X, Nekrassova O, Hyde ME, Compton RG. Anal. Chem 2004;76:5924-5929. [PubMed: 15456316]

97. Valentini F, Salis A, Curulli A, Palleschi G. Anal. Chem 2004;76:3244-3248. [PubMed: 15167808] 98. Zhang M, Gorski W. Anal. Chem 2005;77:3960-3965. [PubMed: 15987097]

99. Karyakin AA, Ivanova YN, Revunova KV, Karyakina EE. Anal. Chem 2004;76:2004-2009. [PubMed: 15053664]

100. Lee Y, Oh BK, Meyerhoff ME. Anal. Chem 2004;76:536-544. [PubMed: 14750844]

101. Cha W, Lee Y, Oh BK, Meyerhoff ME. Anal. Chem 2005;77:3516-3524. [PubMed: 15924383] 
102. Liu S, Volkmer D, Kurth DG. Anal. Chem 2004;76:4579-4582. [PubMed: 15283605]

103. Shin JH, Weinman SW, Schoenfisch MH. Anal. Chem 2005;77:3494-3501. [PubMed: 15924380]

104. Fan C, Liu X, Pang J, Li G, Scheer H. Anal. Chim. Acta 2004;523:225-228.

105. Ghoneim MM, Tawfik A. Anal. Chim. Acta 2004;511:63-69.

106. Wang J, Musameh M. Anal. Chim. Acta 2004;511:33-36.

107. Hayashi K, Iwasaki Y, Horiuchi T, Sunagawa K, Tate A. Anal. Chim 2005;77:5236-5242.

108. Kummer AM, Hierlemann A, Baltes H. Anal. Chim 2004;76:2470-2477.

109. Kuban P, Berg JM, Dasgupta PK. Anal. Chim 2004;76:2561-2567.

110. Chao Y, Yao S, Buttner WJ, Stetter JR. Sens. Actuators, B 2005;B106:784-790.

111. Dutta A, Ishihara T, Nishiguchi H. Chem. Mat 2004;16:5198-5204.

112. Lutz BJ, Fan ZH, Burgdorf T, Friedrich B. Anal. Chem 2005;77:4969-4975. [PubMed: 16053311]

113. Liu Y, Koep E, Liu M. Chem. Mater 2005;17:3997-4000.

114. Kolmakov A, Klenov DO, Lilach Y, Stemmer S, Moskovits M. Nano Lett 2005;5:667-673. [PubMed: 15826106]

115. Bekyarova E, Davis M, Burch T, Itkis ME, Zhao B, Sunshine S, Haddon RC. J. Phys. Chem. B 2004;108:19717-19720.

116. Li X-L, Lou T-J, Sun X-M, Li Y-D. Inorg. Chem 2004;43:5442-5449. [PubMed: 15310226]

117. Buzzeo MC, Hardacre C, Compton RG. Anal. Chem 2004;76:4583-4588. [PubMed: 15283606]

118. Mehrvar M, Abdi M. Anal. Sci 2004;20:1113-1126. [PubMed: 15352497]

119. Lin Y, Yantasee W, Wang J. Frontiers in Bioscience 2005;10:492-505. [PubMed: 15574386]

120. Merkoci A, Pumera M, Llopis X, Perez B, del Valle M, Alegret S. TrAC Trends Anal. Chem 2005;24:826-838.

121. Wang J. Analyst 2005;130:421-426. [PubMed: 15846872]

122. Yanez-Sedeno P, Pingarron JM. Anal. Bioanal. Chem 2005;382:884-886. [PubMed: 15864491]

123. Alaejos MS, Garcia Montelongo FJ. Chem. Rev 2004;104:3239-3266. [PubMed: 15250741]

124. Zhang W, Li G. Anal. Sci 2004;20:603-609. [PubMed: 15116955]

125. Diaz-Gonzalez M, Gonzalez-Garcia MB, Costa-Garcia A. Electroanalysis 2005;17:1901-1918.

126. Cosnier S. Electroanalysis 2005;17:1701-1715.

127. Hart JP, Crew A, Crouch E, Honeychurch KC, Pemberton RM. Anal. Lett 2004;37:789-830.

128. Ju H, Zhao H. Frontiers in Bioscience 2005;10:37-46. [PubMed: 15574345]

129. Kerman K, Kobayashi M, Tamiya E. Meas. Sci. Technol 2004;15:R1-R11.

130. Lawrence NS, Deo RP, Wang J. Anal. Chem 2004;76:3735-3739. [PubMed: 15228348]

131. Pereira CM, Oliveira JM, Silva RM, Silva F. Anal. Chem 2004;76:5547-5551. [PubMed: 15362919]

132. Katz E, Sheeney Haj I, Willner I. Angew. Chem., Int. Ed 2004;43:3292-3300.

133. Kase Y, Muguruma H. Anal. Sci 2004;20:1143-1146. [PubMed: 15352501]

134. Prieto-Simon B, Armatas GS, Pomonis PJ, Nanos CG, Prodromidis MI. Chem. Mater 2004;16:10261034.

135. Liu G, Lin Y, Ostatna V, Wang J. Chem. Commun 2005:3481-3483.

136. Morrin A, Orawan N, Killard A, Moulton S, Smyth M, Wallace G. Electroanalysis 2005;17:423.

137. Zhang M, Smith A, Gorski W. Anal. Chem 2004;76:5045-5050. [PubMed: 15373440]

138. Gavalas VG, Law SA, Christopher Ball J, Andrews R, Bachas LG. Anal. Biochem 2004;329:247252. [PubMed: 15158483]

139. Joshi PP, Merchant SA, Wang Y, Schmidtke DW. Anal. Chem 2005;77:3183-3188. [PubMed: 15889907]

140. Hrapovic S, Liu Y, Male KB, Luong JHT. Anal. Chem 2004;76:1083-1088. [PubMed: 14961742]

141. Lin Y, Lu F, Tu Y, Ren Z. Nano Lett 2004;4:191-195.

142. Patosky F, Weizmann Y, Willner I. Angew. Chem., Int. Ed 2004;43:2113-2117.

143. Chen RJ, Choi HC, Bangsaruntip S, Yenilmez E, Tang X, Wang Q, Chang Y-L, Dai H. J. Am. Chem. Soc 2004;126:1563-1568. [PubMed: 14759216]

144. Yemini M, Reches M, Rishpon J, Gazit E. Nano Lett 2005;5:183-186. [PubMed: 15792436] 
145. Shan D, Mousty C, Cosnier S. Anal. Chem 2004;76:178-183. [PubMed: 14697048]

146. Zhou H, Gan X, Wang J, Zhu X, Li G. Anal. Chem 2005;77:6102-6104. [PubMed: 16159149]

147. Quan D, Shim JH, Kim JD, Park HS, Cha GS, Nam H. Anal. Chem 2005;77:4467-4473. [PubMed: 16013861]

148. Rahman MA, Kwon N-H, Won M-S, Choe ES, Shim Y-B. Anal. Chem 2005;77:4854-4860. [PubMed: 16053298]

149. Rowinski P, Bilewicz R, Stebe M-J, Rogalska E. Anal. Chem 2004;76:283-291. [PubMed: 14719872]

150. Schulze H, Schmid RD, Bachmann TT. Anal. Chem 2004;76:1720-1725. [PubMed: 15018574]

151. Laudet E, Hatz S, Droniou M, Dale N. Anal. Chem 2005;77:3267-3273. [PubMed: 15889918]

152. Shumyantseva VV, Ivanov YD, Bistolas N, Scheller FW, Archakov AI, Wollenberger U. Anal. Chem 2004;76:6046-6052. [PubMed: 15481952]

153. Smutok O, Gayda G, Gonchar M, Schuhmann W. Biosens. Bioelectron 2005;20:1285-1290. [PubMed: 15590280]

154. Ionescu RE, Gondran C, Gheber LA, Cosnier S, Marks RS. Anal. Chem 2004;76:6808-6813. [PubMed: 15538808]

155. Zhang Y, Heller A. Anal. Chem 2005;77:7758-7762. [PubMed: 16316186]

156. Jung HS, Kim JM, Park JW, Lee HY, Kawai T. Langmuir 2005;21:6025-6029. [PubMed: 15952856]

157. Matsuura H, Sato Y, Niwa O, Mizutani F. Anal. Chem 2005;77:4235-4240. [PubMed: 15987132]

158. Fernandez-Sanchez C, McNeil CJ, Rawson K, Nilsson O. Anal. Chem 2004;76:5649-5656. [PubMed: 15456282]

159. Thomas JH, Kim SK, Hesketh PJ, Halsall HB, Heineman WR. Anal. Chem 2004;76:2700-2707. [PubMed: 15144178]

160. Wilson MS. Anal. Chem 2005;77:1496-1502. [PubMed: 15732936]

161. Honda N, Inaba M, Katagiri T, Shoji S, Sato H, Homma T, Osaka T, Saito M, Mizuno J, Wade Y. Biosens. Bioelectron 2005;20:2306-2309. [PubMed: 15797330]

162. Yang L, Li Y, Erf GF. Anal. Chem 2004;76:1107-1113. [PubMed: 14961745]

163. Mak WC, Cheung KY, Trau D, Warsinke A, Scheller F, Renneberg R. Anal. Chem 2005;77:28352841. [PubMed: 15859600]

164. Wang J, Liu G, Munge B, Lin L, Zhu Q. Angew. Chem., Int. Ed 2004;43:2158-2161.

165. Siwy Z, Trofin L, Kohli P, Baker LA, Trautmann C, Martin CR. J. Am. Chem. Soc 2005;127:50005001. [PubMed: 15810817]

166. Schon P, Degefa TH, Asaftei S, Meyer W, Walder L. J. Am. Chem. Soc 2005;127:11486-11496. [PubMed: 16089479]

167. Liu G, Wang J, Kim J, Jan MR, Collins GE. Anal. Chem 2004;76:7126-7130. [PubMed: 15571369]

168. Hernandez-Santos D, Diaz-Gonzalez M, Gonzalez-Garcia MB, Costa-Garcia A. Anal. Chem 2004;76:6887-6893. [PubMed: 15571337]

169. Xie H, Zhang C, Gao Z. Anal. Chem 2004;76:1611-1617. [PubMed: 15018558]

170. Xie H, Yu YH, Xie F, Lao YZ, Gao Z. Anal. Chem 2004;76:4023-4029. [PubMed: 15253638]

171. Dominguez E, Rincon O, Narvaez A. Anal. Chem 2004;76:3132-3138. [PubMed: 15167793]

172. Wang J, Liu G, Jan MR. J. Am. Chem. Soc 2004;126:3010-3011. [PubMed: 15012105]

173. Liu A, Anzai J. Anal. Chem 2004;76:2975-2980. [PubMed: 15144212]

174. Dennany L, Forster RJ, White B, Smyth M, Rusling JF. J. Am. Chem. Soc 2004;126:8835-8841. [PubMed: 15250737]

175. Kim K, Yang H, Park SH, Lee D-S, Kim S-J, Lim YT, Kim YT. Chem. Commun 2004:1466-1467.

176. Di Giusto DA, Wlassoff WA, Giesebrecht S, Gooding JJ, King GC. Angew. Chem., Int. Ed 2004;43:2809-2812.

177. Fojta M, Havran L, Vojtiskova M, Palecek E. J. Am. Chem. Soc 2004;126:6532-6533. [PubMed: 15161263]

178. Reisberg S, Piro B, Noel V, Pham MC. Anal. Chem 2005;77:3351-3356. [PubMed: 15889928] 
179. Le Floch F, Ho H-A, Harding-Lepage P, Bedard M, Neagu-Plesu R, Leclerc M. Adv. Mater 2005; $17: 1251-1254$.

180. Peng H, Soeller C, Vigar N, Kilmartin PA, Cannell MB, Bowmaker GA, Cooney RP, Travas-Sejdic J. Biosens. Bioelectron 2005;20:1821-1828. [PubMed: 15681199]

181. Pumera M, Castaneda MT, Pividori MI, Eritja R, Merkoci A, Alegret S. Langmuir 2005;21:96259629. [PubMed: 16207045]

182. Kerman K, Morita Y, Takamura Y, Ozsoz M, Tamiya E. Anal. Chim. Acta 2004;510:169-174.

183. Erdem A, Pividori MI, del Valle M, Alegret S. J. Electro. Chem 2004;567:29-37.

184. Kerman K, Morita Y, Takamura Y, Tamiya E. Anal. Bioanal. Chem 2005;381:1114-1121. [PubMed: 15770476]

185. Kerman K, Morita Y, Takamura Y, Ozsoz M, Tamiya E. Electroanalysis 2004;16:1667.

186. Cai W, Peck JR, Weide DWvd, Hamers RJ. Biosens. Bioelectron 2004;19:1013-1019. [PubMed: 15018956]

187. Uslu F, Ingebrandt S, Mayer D, Bocker-Meffert S, Odenthal M, Offenhausser A. Biosens. Bioelectron 2004;19:1723-1731. [PubMed: 15142607]

188. Kim D-S, Jeong Y-T, Park H-J, Shin J-K, Choi P, Lee J-H, Lim G. Biosens. Bioelectron 2004;20:69_ 74. [PubMed: 15142578]

189. Sakata T, Miyahara Y. ChembioChem 2005;6:703-710. [PubMed: 15812785]

190. Yang W, Hamers RJ. Langmuir 2004;20:6778-6787. [PubMed: 15274585]

191. Gu H, Su Xd, Loh KP. Journal of Physical Chemistry B 2005;109:13611-13618.

192. Long Y-T, Li C-Z, Sutherland TC, Kraatz H-B, Lee JS. Anal. Chem 2004;76:4059-4065. [PubMed: 15253643]

193. Xu D, Xu D, Yu X, Liu Z, He W, Ma Z. Anal. Chem 2005;77:5107-5113. [PubMed: 16097746]

194. Rodriguez MC, Kawde A-N, Wang J. Chem. Commun 2005;34:4267-4269.

195. Bang GS, Cho S, Kim B-G. Biosens. Bioelectron 2005;21:863-870. [PubMed: 16257654]

196. Xiao Y, Piorek BD, Plaxco KW, Heeger AJ. J. Am. Chem. Soc 2005;127:17990-17991. [PubMed: 16366535]

197. Babkina SS, Ulakhovich NA, Zyavkina YI. Anal. Chim. Acta 2004;502:23-30.

198. Babkina SS, Ulakhovich NA. Anal. Chem 2005;77:5678-5685. [PubMed: 16131081]

199. Liu J, Roussel C, Lagger G, Tacchini P, Girault HH. Anal. Chem 2005;77:7687-7694. [PubMed: 16316177]

200. Li C-Z, Liu Y, Luong JHT. Anal. Chem 2005;77:478-485. [PubMed: 15649043] 